\title{
¿ES NECESARIA Y POSIBLE UNA TEORÍA GENERAL PARA ESTRUCTURAR LA CIENCIA CONTABLE?*
}

\author{
JOSÉ JOAQUÍN ORTIZ BOJACÁ** \\ UNIVERSIDAD LIBRE (BOGOTÁ, COLOMBIA)
}

Recibido/ Received/ Recebido: 01/11/2012 - Aceptado/ Accepted / Aprovado: 30/04/2013

\begin{abstract}
Resumen
En este artículo bosqueja un conjunto de argumentos enfocados en el objeto de la ciencia contable, la interdisciplinariedad y transdisciplinariedad, y la complejidad; todos ellos como elementos claves en la estructuración de la teoría general de la contabilidad. Sin embargo, se identifica que la ciencia contable no ha logrado un nivel maduro de estructuración científica por las razones que se convierten en el eje central de esta disertación. Se analizan dos de los principales pensadores contables, Richard Mattessich y a Antonio Lópes de Sá, para confrontar y evaluar sus respectivos modelos frente al marco epistemológico, referente a la construcción y consolidación de la ciencia contable. Se propone caminos para recabar el diseño de la estructura general del cuerpo teórico y sus implicaciones. Palabras clave: Interdisciplinariedad, Transdisciplinariedad, Teoría general, Epistemología contable, Complejidad.
\end{abstract}

\section{A GENERAL THEORY TO STRUCTURE ACCOUNTING SCIENCE NECESSARY AND POSSIBLE?}

\begin{abstract}
This article outline a set of arguments focused on accounting science, interdisciplinarity, transdisciplinarity and compexity; as key elements in the structure of general accounting. However accounting science has not achieved a solid level of scientific structure due to reasons that are going to be the central axis of this dissertation. Two of the main representatives of accounting science are analyzed, Richard Mattessich and Antonio Lópes de Sá, in order to compare and evaluate their models against epistemological frameworks, related to the accounting science construction and consolidation. This article proposes ways to achieve a general structure design of the theory and its implications.

Keywords: Interdisciplinarity, Transdisciplinarity, General theory, Accounting epistemology, Complexity.
\end{abstract}

* Resultados del proyecto "Construcción de una teoría general contable", financiado por la Universidad Libre de Bogotá.

** Economista de la Universidad Jorge Tadeo Lozano y Magister en Ciencias financieras y sistemas de la Universidad Central (Colombia). Docente investigador de la Universidad Libre de Bogotá. Correo electrónico: jjoaquin.ortiz@gmail.com, josej.ortizb@unilibrebog.edu.co 


\title{
É NECESSÁRIA E POSSÍVEL UMA TEORIA GERAL PARA ESTRUTURAR A CIÊNCIA CONTÁBIL?
}

\begin{abstract}
Resumo
O artigo desenha um conjunto de argumentos enfocados no objeto da ciência contábil, na interdisciplinaridade, na transdisciplinaridade e na complexidade, todos eles como elementos centrais na estruturação da teoria geral da contabilidade. No entanto, identifica-se que a ciência contábil não conseguiu um nível maduro de estruturação científica pelas razões que compõem o eixo central desta dissertação. Analisam-se dois dos principais pensadores contábeis, Richard Mattessich e Antonio Lópes de Sá, para confrontar e avaliar seus respectivos modelos frente ao marco epistemológico, referente à construção e consolidação da ciência contábil. Propõem-se caminhos para reivindicar o desenho da estrutura geral do corpo teórico e seus envolvimentos

Palavras chave: Interdisciplinaridade, Transdisciplinaridade, Teoria geral, Epistemologia contábil, Complexidade.

Ortiz, J. (2013) ¿Es necesaria y posible una teoría general para estructurar la ciencia contable?. En: Revista de la Facultad de Ciencias Económicas de la Universidad Militar Nueva Granada. rev.fac. cienc.econ, XXI (2)
\end{abstract}

JEL: M19, C61, M41, G10, A10.

\section{Introducción}

Si cuestionamos el desarrollo que ha tenido la ciencia contable como tal, es interesante comprender que se ha ido generando una tendencia a priorizar el establecimiento de normas sobre procedimientos para categorizar la información, clasificarla, organizarla, interpretarla para un fin determinado, específicamente al servicio del capital y de sus propietarios, con lo cual se ha alcanzado un desarrollo de una técnica muy depurada y sofisticada, que es lo que ha impulsado el modelo anglosajón y todas sus instituciones contables (Montilla et al, 2005). Ello ha creado un obstáculo epistemológico, para avanzar a una siguiente etapa, que consiste en buscar las explicaciones del comportamiento de lo que tan técnicamente se ha medido y ha representado. Para comprender sus movimientos es necesario reconocer las relaciones sociales inmersas en la generación y acumulación del capital, así como sus consecuencias derivadas, como lo son la distribución de la riqueza y sus impactos humanos y sociales. En ese marco entrar al tema de la explicación de los fenómenos que no son solo económicos sino sociales, es algo que no ha sido prioritario para quienes se benefician del actual modelo de representación contable (Franco, 2011). Es como si en la física el hombre se hubiera conformado con haber aprendido a medir las distancias, pero no a relacionarlas con el movimiento de los cuerpos, evaluando los tiempos implicados, hasta llegar a entender la atracción de los cuerpos, y así comprender todo el fenómeno explicado por la mecánica. Lo que sucede es que en ciencias sociales, la mediación del poder subyacente, opaca el interés científico, en aras de una finalidad particular y no con la mirada social del bien común y general (Bourdieu, 2003).

Ello explicaría por qué para la ciencia económica, se ha resuelto el problema de la producción, pero no se ha avanzado suficientemente en el problema de la distribución de la riqueza, y de paso la contabilidad como ciencia se ha quedado en la representación de la acumulación del capital y tampoco ha aportado significativamente a la representación del problema de la distribución. De allí se derivaría por qué se ha confundido al dar el estatus de técnica a la contabilidad al servicio de la ciencia económica o del Derecho, que como lo decíamos, desde esta perspectiva lo ha hecho muy bien, mientras se diluye la verdade- 
ra discusión sobre qué es lo que debe explicar, comprender, analizar e interpretar, la contabilidad como ciencia. Ello también se trasluce en la formación profesional de los contadores, que se ha enfocado más hacia la enseñanza de los procedimientos mecánicos de la técnica de la contabilización, que hacia la fundamentación de los conceptos en los que se apoya la norma que se está aplicando (Gómez, 2012).

Uno de los problemas no abocado suficientemente es el impacto medioambiental que tienen las acciones del hombre y de sus instituciones y que en últimas es lo que se trata de abordar como responsabilidad social empresarial, pero que no está contemplada en las premisas fundamentales de la ciencia contable, bajo el paradigma dominante (Rodríguez, 2011).

El estado actual del desarrollo de la disciplina contable exige el desarrollo de una estrategia de fortalecimiento del pensamiento contable-financiero que permita potenciar la generación de conocimiento alrededor de las disciplinas contable-financiera, administrativa y económica, girando alrededor de una médula espinal neurálgica y a su vez interdisciplinaria y transdisciplinar, constituida por la necesidad de consolidar una teoría general de la contabilidad como ciencia, lo que exige una visión compleja, transdisciplinar, interdisciplinar, integral y holística, tópico éste, eminentemente epistemológico (Ortiz, 2009).

Es en ese contexto donde se pretende responder la pregunta con que se titula este artículo, que consideramos es una deuda que tiene la disciplina contable frente a su desarrollo. Ello tiene una consecuencia inmediata en el proceso de consolidación de la ciencia contable, que a estas alturas del desarrollo económico y social, reclama respuestas vitales.

En el proceso de consolidación de la contabilidad como ciencia es de reconocer que aún falta la consolidación de una estructura formal de una teoría general (Chatfield, 1979; Fernández, 2003) que le permite avanzar en la definición de un cuerpo teórico integrado que dé respuesta a muchos problemas. Estos se abordan en forma independiente y aislada, gestando una dispersión de esfuerzos tanto teóricos como pragmáticos, lo cual se refleja en una separación entre teoría y práctica, que aún no encuentran la forma de integración y que básicamente se explica por la carencia de esa formalización de la teoría general de la contabilidad: "No hay duda de que existe un bagaje de conocimiento teórico conceptual, pero éste aún reclama una Teoría General compartida tanto por el ámbito doctrinario como por el profesional... Esta teoría debería incluir y relacionar todas las especialidades contables (patrimonial, social, gerencial, pública, etc.), con sus enfoques doctrinario y normativo, los modelos en ellas generados así como sus aplicaciones" (Fernández, 2003).

Se colige que en este proceso de consolidación de la contabilidad como ciencia, es importante desarrollar un marco comprensivo que permita un abordaje integrador desde lo multidisciplinar, lo interdisciplinar y lo transdisciplinar, de tal manera que se logre una visión holística de la disciplina, sin que ello signifique eliminar la diversidad del pensamiento, sino al contrario establecer el diálogo de saberes bajo un enfoque sistémico, que es lo que se debe buscar con la estructuración de una teoría general de la contabilidad (Villarreal, 2009).

Es muy pertinente recabar el concepto de teoría general contable y a partir de allí derivar los componentes que debe contener. Para Túa Pereda (1995) esa teoría general hace referencia al conjunto de hipótesis sobre lo que tienen en común todos los sistemas contables. Para Mattessich (2002) es el marco universal para la conceptualización de los diferentes sistemas contables existentes.

Se pueden abordar diferentes enfoques para estructurar el conjunto de premisas fundamentales, que debe contener un cuerpo de teoría general de la contabilidad y desde allí se estaría estableciendo el enfoque que se le asigna a la contabilidad como ciencia. Para el caso es muy importante reseñar la estructura fundamental que propone Matessich (2002): Unidad monetaria, unidad de tiempo, estructura, dualidad, acumulación, objetos económicos, unidad de medida estable, agentes económicos, entes, transacciones económicas, valuación, realización, clasificación, ingreso de datos, duración o periodo, consolidación, significatividad, asignación o imputación. Como se observa el enfoque prioritario es la medición de la riqueza desde el aspecto económico, centrado en 
las unidades sociales. También López de Sá (1992, 2007), ha efectuado importantes avances en ese sentido, sobre todo integrando explicaciones sobre las dinámicas patrimoniales, que bien vale la pena analizar y evaluar en el diseño de ese marco estructurante de la teoría general contable.

Este artículo presenta los resultados de la investigación efectuada alrededor de este tema que a pesar de que no ha recibido todos los esfuerzos que se requieren para impulsar su desarrollo, es crucial para la disciplina contable. Ello lo haremos a través del desarrollo de los siguientes tópicos:

- Obstáculos epistemológicos en la consolidación de una teoría general de la ciencia contable

- ¿Qué significa el desarrollo de una teoría general en las ciencias sociales y especialmente en la ciencia contable?

- ¿En qué nivel de teorización se encuentra la contabilidad?

- Dos enfoques de la teoría general contable actuales.

- Hacia una propuesta de estructuración de la teoría general contable.

A continuación se desarrollan estos tópicos:

\section{Obstáculos epistemológicos en la con- solidación de una teoría general de la ciencia contable}

Es importante determinar una serie de obstáculos epistemológicos (Bachelard, 1987) que no han permitido una consolidación de una teoría general contable y que son el resultado natural de un proceso de forcejeos ideológicos, pragmáticos y como lo plantea Bourdieu (1999) de lucha de poder por la apropiación del capital simbólico, que finalmente determinan la estructura del campo contable. A continuación se analizan esos obstáculos significativos, desde la perspectiva epistemológica, para esclarecer el camino que conduce a la consolidación de las bases estructurales de la teoría general contable.

\subsection{Las relaciones entre el sujeto y el objeto de la ciencia contable}

Para empezar a ubicar el problema de la epistemología contable es interesante abordar las relaciones entre sujeto y objeto (Horkheimer, 2000), pues desde aquí, es cómo podemos comprender, que la Contabilidad como ciencia social, está exigiendo nuevos enfoques que nos permitan escudriñar una visión más compleja, y así vislumbrar la posibilidad o no y la necesidad o no de una teoría general contable.

En la relación sujeto-objeto, es necesario cuestionar desde la perspectiva del problema del conocimiento, si realmente existen como premisas, las siguientes, que se consideraban inamovibles desde la perspectiva de la corriente tradicional de la teoría contable:

"•La teoría está separada de lo observado. - La realidad empírica es objetiva y externa al sujeto. • Se asume que el único propósito de las firmas y de los individuos es la maximización de la utilidad. $•$ Las organizaciones y las sociedades son en esencia estables. $\bullet \mathrm{El}$ mecanismo que resuelve los conflictos es el control. $\cdot$ La contabilidad se preocupa por los medios y no por los fines, por lo que no se cuestionan las organizaciones sociales en las que se está inmerso." (Chua, 1986, 48).

Frente a esta corriente se encuentra otra perspectiva, la de la corriente interpretativa, que considera de una manera diferente la relación objeto-sujeto:

"•Se buscan explicaciones científicas de la intención humana. - Se estimula la observación participante. $\cdot$ La realidad social es emergente, creada subjetivamente y objetivada a través de la interacción humana. - Todas las acciones tienen un significado y una intención. • Existe un orden social, lo que permite resolver el conflicto a través de esquemas comunes de significados sociales. $\cdot$ La teoría busca comprender cómo se produce y se reproduce el orden social." (Chua, 1986, 54).

En este primer aspecto se puede concluir que la construcción de una teoría general contable exige 
partir de una premisa fundamental: Reconocer la interacción entre el sujeto que en nuestro caso es el Contador y la sociedad a la que sirve, que impacta y a su vez es impactado por los procesos de captación, simbolización, medida, valoración, representación, coordinación, agregación, análisis e interpretación, lo que exige redefinir los elementos determinantes de esa relación de tal manera que se conviertan en premisas fundamentales de todo el sistema, problema que debe ser abocado por la estructuración de una teoría general de la contabilidad.

\subsection{La definición del objeto de estudio}

Otro problema que se puede constituir en un obstáculo a la consolidación de una teoría general contable es la delimitación del objeto de estudio de la ciencia contable. Este aspecto pareciera estar resuelto para que pudiéramos hablar de una ciencia contable, pero realmente la situación por lo menos no es tan clara como se puede percibir en otras ciencias sociales como la economía, la administración, la sociología, etc. Se podría afirmar que el proceso de consolidación de una ciencia, que inicialmente surge como respuesta a problemáticas concretas, continúa luego un proceso normal de formalización, que entre otras cosas exige una delimitación del objeto de estudio, es decir del tipo de fenómenos en los que se quiere concentrar el análisis para explicar por qué se desarrollan de una u otra forma dichos fenómenos (Morín, 1985).

Otra forma de delimitar ese objeto es definir el enfoque bajo el cual se quiere entender ese tipo de fenómenos, originándose la posibilidad de que un mismo tipo de fenómenos sea observado desde diferentes perspectivas. Desde la fundamentación de las ciencias de la vida se puede afirmar que todas tienen la misma finalidad: la vida (Capra, 2004), y a partir de allí empezar a deslindar objetos o perspectivas propias desde las cuales se pretende abordar el conocimiento propio. Desde esa perspectiva es que se debe entender la interdisciplinariedad y la transdisciplinariedad que en la actual etapa del desarrollo científico está buscando reintegrar esas miradas, lo que empieza a romper las tradicionales talanqueras ente las diferentes ciencias rescatando la necesidad de cooperación e interacción entre métodos, herramientas e instrumentos, de los diversos campos de la ciencia.
Pero lo que es el retornar de las ciencias maduras a sus necesarias interdependencias, hasta ahora sólo ha sido un obstáculo epistemológico para la consolidación de la ciencia contable que en su proceso de desarrollo ha ido ganando autonomía frente a sus correlativas que podríamos denominar ciencias de la riqueza como la economía, la administración, las finanzas, el derecho. En ese proceso se ha confundido el método con el objeto de la contabilidad, pues algunos autores la tipifican como si su objeto fuera la información relativa a la medición de los fenómenos económicos, lo que prácticamente la convertiría en una técnica al servicio de la ciencia económica, o como si su objeto fuera el atestamiento de los derechos de propiedad y de los derechos patrimoniales convirtiéndola en una técnica o herramienta auxiliar de la ciencia del derecho. Esta fase se ha venido superando y la discusión se ha centrado en verdaderos objetos de estudio de la ciencia contable:

"Varios otros autores, entre ellos, Rafael Franco, Danilo Ariza, Jorge Burbano, Edgar Gracia y otros han aportado acerca de cuál es el objeto de la contabilidad y han dicho, por ejemplo: Rafael, que es la riqueza. Yo mismo escribí alguna vez que era la Utilidad $y$ ahora estoy diciendo que son los recursos. Danilo Ariza, por ejemplo, afirma que es el patrimonio, últimamente ha propuesto que es el control y muchos otros hablan de que es la información" (Araujo, 2007).

Como se puede apreciar los ribetes que ha adquirido esta delimitación muestra diversas miradas, algunas de ellas sólo diferenciadas en su forma, otras que asumen el objeto de la ciencia contable como los objetivos de la misma, por ejemplo cuando se establece como objeto de estudio el control, siendo éste uno de sus posibles objetivos, pero lo cierto es que cada vez se da una mayor aproximación al verdadero objeto. En esa dirección se observa que la diferencia termina siendo terminológica: Riqueza, Patrimonio y Recursos, que cuando se examina a profundidad se detecta cierta identidad en la esencia de los mismos:

"Podríamos comenzar por situar el objeto de estudio de muchas ciencias tanto físicas 
como sociales, desde un punto de vista de la finalidad última que hace coincidir en lo que realmente buscan en beneficio del hombre y es lo que se conoce como la riqueza, entendida ésta como un conjunto de medios para la satisfacción de las necesidades humanas. Lo que diferencia las posibilidades de abordaje del conocimiento de la riqueza, es el enfoque o el prisma bajo el que se mira, lo que permite una especialización de la ciencia, pero también desde otra óptica que ha sido descuidada en beneficio de esa especialización, permite una integración sistémica de los conocimientos, que es lo que se conoce como la interdisciplinariedad y la transdisciplinariedad de la ciencia. Esta aproximación epistemológica de la ciencia, nos brinda una visión panorámica, que facilita su entendimiento desde una perspectiva sistémica y holística, como un primer paso hacia el reconocimiento de la complejidad de la misma. Este concepto de riqueza se ha hecho equivalente al de PATRIMONIO, por parte del estudioso brasilero Lópes de Sá (1997), del cual se deriva toda una estructura teorética de la Contabilidad como ciencia" (Ortiz, 2012).

Este proceso se convierte en fundamental para la estructuración de una teoría general de la Ciencia Contable pues la identidad de su objeto no sólo tiene que ser real sino formal, lo cual exige un gran esfuerzo de los investigadores para establecer un acuerdo en este referente y las premisas deben estar orientadas a precisar estos componentes.

\subsection{La estructuración del método contable}

En el establecimiento de una teoría general de la contabilidad, otro tópico clave en la estructura formal de la misma es la definición del método contable (Avellaneda \& Ortiz, 2012) entendiendo éste como la forma de abordar el objeto de estudio para explicar su realidad. Si se concibe su estructura como un conjunto de componentes integrados, y a partir de allí empezar a diseñar esa visión bajo una perspectiva sistémica, es importante recurrir al modelo que nos presenta el estudioso Roberto Gómez López, que conceptualiza el método contable de la siguiente manera:
"La Contabilidad desarrolla una metodología específica para obtener y suministrar información del estado y evolución de determinadas realidades económicas; se materializa en las funciones de captación, simbolización, medida, valoración, representación, coordinación, agregación, que junto a las de análisis e interpretación, y sirviéndose inicialmente de un proceso de inducción que posteriormente se torna en deductivo, permite la obtención de la realidad económica revelada, representativa, en términos contables, de una realidad que mediante una simple observación se presentaría inexpresiva y desordenada" (Gómez, 2009, 7).

Es importante resaltar el conjunto de los componentes expuestos que se muestran como elementos de la metodología científica en la construcción de la teoría científica de la Contabilidad, los cuales se consideran válidos como un enfoque general que recoge todos los elementos que se deben considerar en el proceso de estructurar la teoría general contable, con lo cual se empieza a dar respuesta en sus aspectos básicos al cuestionamiento sobre la necesidad y viabilidad de desarrollar esa teoría general de la contabilidad. Más adelante volveremos sobre este tópico, cuando se desarrolle el tema de los componentes fundamentales de una teoría general contable. Lo importante por ahora es dejar establecido que en la formalización es necesario incluir las premisas que se encarguen de fundamentar el enfoque metodológico de la ciencia contable que haga coherente todo el sistema de soporte de una estructura científica y donde la relación coherente objetivos-métodos sea el enfoque general estructurante, lo cual recogeremos bajo un concepto integrador del método científico contable que está siendo reconocido, y es el de "Contametría" (Ortiz, 2012), que desarrollaremos más adelante.

\subsection{La interdisciplinariedad y transdisciplina- riedad en la ciencia contable}

Es interesante puntualizar el papel que juega la interdisciplinariedad y la transdisciplinariedad en el entramado de una teoría general de la ciencia contable. Para ello debemos partir de una premisa epistemoló- 
gica, que rebasa el modelo tradicional de la construcción de la ciencia y es partir de reconocer que en el ordenamiento teórico de las disciplinas (Garciandía, 2011) que afrontan la comprensión de la riqueza en su función de satisfacer la necesidades humanas de los grupos sociales, existen una serie de interrelaciones que es necesario identificar y reconocer, para a partir de allí esclarecer el campo propio de cada una de ellas, que determinan su autonomía, así como los puntos comunes y los tipos de influencias mutuas, que deben hacer parte de sus estructuras científicas, lo que implica reconocer la comunidad en algunas herramientas, instrumentos y métodos, que se pueden y algunas veces se deben compartir, sin que se pierda el objetivo final de cada una ni se pierda en una nebulosa el objeto y campo propio, lo cual podría frenar el desarrollo de alguna de ellas en detrimento de otras, sino que su mutuo apoyo desemboque en una plena autonomía (Luhmann, 1990).

Encontrar esos puntos de contacto y de intercambio en múltiples vías de interacción e injerencia mutua entre las ciencias de la vida es un factor coadyuvante en el desarrollo científico de todas ellas, pero especialmente para la Contabilidad que está en proceso de consolidación y cuya autonomía se ha puesto en duda por razones históricas que creemos hacen parte de toda la historia de las ciencias pero que madurando su estructura general está demostrando que tiene un campo propio (el análisis de las dinámicas patrimoniales económicas, culturales, territoriales y sociales) y que desde luego se verá autenticado con la consolidación de una teoría general de la contabilidad como ciencia, que está en proceso de construcción.

Ahora es interesante comprender de qué manera la transdisciplinariedad contribuye a la consolidación de una teoría general de la contabilidad entendiendo que en un nivel superior de las ciencias a manera de un supra-sistema es posible transpolar algunos elementos de una de ellas para las demás pero a su vez el conjunto de ciencias afines se pueden alimentar de los modelos construidos en todas ellas. Para ello se trae a colación al estudioso contador colombiano, el profesor Avellaneda quien en un ingenioso y valioso ejercicio intelectual traslada elementos de la física a la Contabilidad:
"Los ciclos de operaciones financieras tienen similitud con el funcionamiento y estructura del átomo, y conforma igualmente estructuras que permiten la comprensión y el estudio de la información contable y financiera en sus diferentes formas, facilitan la medición y la predicción de los hechos económicos y del patrimonio resultante. $\mathrm{Su}$ periferia la conforman los hechos económicos, su núcleo está formado por los procesos contables y el movimiento está dado por las decisiones de los administradores". (Avellaneda, 2009, 216).

De esa manera se pueden seguir investigando elementos comunes entre las ciencias, como también lo hizo el profesor Requena (1977), quien utiliza el teorema $\pi$ proveniente del campo de la física, en su texto "La homogenización de magnitudes en la ciencia de la Contabilidad", de donde tomamos la siguiente cita:

"Definidos, pues, los conceptos fundamentales -magnitudes y productos dimensionales $y$ adimensionales y funciones dimensionalmente homogéneas - del análisis dimensional, completamos el mismo con el denominado teorema $\pi$, de singular interés para la obtención de ecuaciones que relacionen las variables que intervienen de alguna forma en un fenómeno" (Requena, 1977, 102).

\subsection{La complejidad y la ciencia contable}

Las bases de las ciencias sociales se están reestructurando bajo el paradigma de la complejidad, permitiendo comprender mejor los fenómenos humanos, que por esencia son complejos, lo cual es plenamente válido para la ciencia contable. Ello significa la sustitución de principios que caracterizaron un modelo de ciencia unidireccional y mecánica, por otros principios como el de la recursividad, la emergencia, la dualidad de lo objetivo y lo subjetivo, la autopoiesis, la autoorganización, las relaciones circulares, las interrelaciones y la influencia mutua en ciclos en espiral de causas a efectos, etc. (Morin, 2000; Maturana, 1990). 
El análisis de la complejidad es un elemento integrador que enriquece todo el entramado de la construcción de una teoría general de la ciencia contable, permitiendo resolver enigmas que no han sido abordados lo suficientemente, desde los principios como los mencionados anteriormente, pero que merecen ser abordados con mayor profundidad, como parte de un programa de investigación en la construcción de la teoría general de la Contabilidad, y que se plantea como una propuesta para la profesión, para la academia y para la investigación.

Una síntesis de los obstáculos que enfrenta el desarrollo de la teoría general contable podría resumirse en los siguientes aspectos relevantes: (i) Discusión inconclusa sobre el objeto de estudio de la Contabilidad como ciencia. (ii) Desarrollo epistemológico insuficiente sobre las bases explicativas del fenómeno objeto del campo contable. (iii) Incomprensión del modelo diferenciador entre la lógica interpretativa, comprensiva y explicativa del campo científico de la contabilidad, frente al desarrollo de la técnica y la tecnología con una visión parcial y parcializada de las relaciones medios-fines que busca satisfacer los intereses de información para la acumulación del capital, dejando de lado los demás componentes sociales. (iv) Una mirada tradicional heredada del positivismo que simplifica artificiosamente las relaciones entre objeto-sujeto, en aras de un objetivismo que excluye las múltiples relaciones y los procesos autopoiéticos y auto-organizadores de la sociedad y sus actores fundamentales. (v) Exclusión de la dialéctica y la hermenéutica, como herramientas de análisis e interpretación de la lógica de los fenómenos objeto de la ciencia contable. (vi) Problemas metodológicos no resueltos sobre medición, valoración y representación contable, que debilitan la confiabilidad de los análisis científicos de la Contabilidad.

Frente a esta serie de obstáculos epistemológicos se abre un amplio espectro de oportunidades desde el paradigma de la complejidad, el enfoque sistémico y el desarrollo del pensamiento crítico-interpretativo, que tratan de superar tales obstáculos. El anterior inventario de obstáculos y oportunidades para el desarrollo epistemológico de una teoría general contable, se puede considerar una muestra representativa, aunque no exhaustiva ni totalmente completa, pero que permite el abordaje a mayor profundidad de las condiciones para ir logrando esa consolidación. Ahora se debe escrutar un aspecto epistemológico muy relevante penetrando al corazón de la estructuración de dicha teoría, iniciando por cuestionar el significado de lo que son leyes y teoría en la ciencia contable, lo cual se desarrolla en el siguiente apartado.

\section{3. ¿Qué significa el desarrollo de una teo- ria general en las ciencias sociales y es- pecialmente en la ciencia contable?}

Para responder esta pregunta es necesario discurrir sobre el concepto de "teoría" y su papel en la estructuración de una ciencia, y de esa manera poder definir el grado de desarrollo logrado por la contabilidad, desde la perspectiva de su nivel científico.

Se puede considerar una teoría como un sistema unificador que estructura en forma orgánica el conjunto de explicaciones de un grupo de hechos interrelacionados, que se expresa en principios, hipótesis y leyes, que también se integran de manera lógica y coherente (Nagel, 1968). Epistemológicamente e históricamente, se considera que las leyes, por lo menos como se entienden en las ciencias naturales, fueron las primeras piezas del conocimiento que se construyeron, y que buscaban describir más que explicar las estructuras de las realidades observadas.

En una etapa subsiguiente, al avanzar las ciencias naturales en la identificación de las relaciones existentes entre los fenómenos, que se expresan en leyes científicas a un nivel de abstracción superior, el interés se vuelca a integrar todos esos conocimientos en sistemas explicativos e integrados de conocimientos que conforman diferentes tipos de teorías (Bunge, 1996). Al organizarlas alrededor de un eje específico, en ámbitos integradores que unifican e identifican una faceta de la realidad para explicarla, se genera un objeto de estudio, que delimita el campo de una "Disciplina". En las ciencias sociales se puede hablar de leyes, aunque no en el mismo sentido que en las ciencias naturales (Mardones, 1994), pues no se puede buscar la exactitud en los fenómenos humanos que por su misma naturaleza, se caracterizan más por la incertidumbre, que se encuentra mejor estudiada desde la complejidad. 
Lo que no es tan claro es que las diferentes teorías desarrolladas al interior de cada disciplina se hayan integrado en un nivel superior, de tal manera que se pueda hablar de una teoría general que integre en forma lógica y coherente a manera de suprasistema o metateoría, las diferentes teorías dentro de una disciplina. Sin embargo con el nacimiento y desarrollo de la teoría general de sistemas (TGS), se empieza a buscar dicha integración, ya no solo al interior de cada disciplina, sino entre ellas, gestándose el paradigma de la complejidad, que abre el campo de la multidisciplinariedad, la interdisciplinariedad, la transdisciplinariedad, lo cual refuerza el enfoque sistémico en el abordaje del conocimiento científico. Esto exige entender cuál ha sido el aporte de la TGS, en el actual desarrollo científico a nivel general para luego observarlo a nivel del esfuerzo de la construcción de una teoría general contable.

Uno de los objetivos de la TGS (Bertalanffy, 2006) es encontrar las propiedades comunes de diferentes objetos de estudios que se relacionan sistémicamente, pero que han sido estudiados en forma particular por cada disciplina, que se limitan a un objeto específico. Ello permite afirmar que la TGS privilegia el enfoque interdisciplinar y transdisciplinar de la ciencia. La Teoría general de sistemas se basa en principios como la subsidiariedad, recursividad, multi-causalidad, complementariedad, entre otros, apartándose así del paradigma de la ciencia clásica; observa totalidades, y busca similitudes entre las regularidades descubiertas en varias disciplinas para integrarlas y transpolar a otro conjunto de disciplinas, reconociendo así la complejidad de la realidad. Todo ello ha incidido para que las diferentes disciplinas busquen al interior, la unificación y consolidación de sus diferentes teorías en una teoría general, como lo veremos más adelante.

Ahora se torna importante regresar a estudiar la base de la estructura científica de las disciplinas, pues de alguna forma, este análisis se inició para evaluar el desarrollo científico de la contabilidad, que es tal vez una de las más jóvenes, y que se reconoce entre los expertos, está en proceso de construcción, por lo que sus mayores esfuerzos se han hecho en el establecimiento de sus bases científicas como lo podemos observar en todo el proceso de axiomatización lle- vado adelante por Mattessich (2002) y por Lopes de Sá (1992).

En las ciencias formales que se caracterizan por no tener un referente empírico, sino que más bien establecen los ordenamientos lógicos que guían el pensamiento científico, como las matemáticas, el cálculo, la geometría y la lógica, es importante seguir el pensamiento Kantiano, pues más que teorías que expliquen fenómenos de la realidad, se configuran sistemas axiomáticos alrededor de teoremas, premisas y axiomas, que sirven de soporte estructural a los esquemas científicos de cualquier ciencia fáctica. Según Kant (1984), uno de los principios de la ciencia es la posibilidad de concebir juicios sintéticos a priori, y tales juicios son base fundamental de las afirmaciones generales de la matemática.

Las ciencias incorporan presupuestos metafísicos y presupuestos lógicos, en su objeto y método respectivamente, y es la Lógica, como componente fundamental de la filosofía, la encargada de estudiar la validez de tales presupuestos y de cómo se da la unificación del objeto y del método. Hay un ordenamiento lógico de deducciones donde de unos enunciados primarios se van deduciendo otros, lo cual exige que los más básicos no sean deducidos de ningún otro y a partir de ellos se deduzcan los demás, son los que se denominan axiomas. Ellos le dan el nombre a todo el sistema de formalización de la ciencia, conocido como axiomático, que asegura la rigurosidad y sistematicidad, que van de los conceptos a las teorías pasando por las hipótesis, las leyes y los modelos. Este ha sido uno de los avances importantes logrados en el desarrollo de la ciencia contable y su axiomatización se le reconoce a algunos estudiosos entre los que descolla Mattessich, como lo veremos en el siguiente apartado.

Sin embargo el proceso de construcción científico solo se demuestra si se logra un desarrollo integral y completo partiendo de premisas fundamentales, deduciendo y construyendo hipótesis y leyes, hasta alcanzar las teorías que expliquen los fenómenos objeto de estudio de la respectiva disciplina y mejor aún si se logra la consolidación de una teoría general. Por ello se va a proseguir el análisis evolutivo del proceso de construcción de conceptos, hipótesis y 
leyes en términos generales y más específicamente a la luz de la disciplina contable. La formación de conceptos es el primer paso en la estructuración de cualquier ciencia, lo cual no significa que estos precedan a la definición de los axiomas, sino que el sentido de aquellos es lo suficientemente conocido, lo que permite incluirlos en los axiomas y que el valor de éstos se evalúa por la evidencia. La clave está en las relaciones que se establezcan entre los conceptos, expresadas en los axiomas, que se suponen verdaderos en la interpretación de los conceptos. Ello implica que la construcción de una ciencia supone una comunidad científica, que valida esos conceptos. Tal vez el concepto primigenio más importante para la contabilidad es el de cuenta y en su desarrollo histórico el de riqueza o patrimonio. Es alrededor de ellos y otros fundamentales, que se hace pertinente construir un sistema axiomático, que permita construir hipótesis, leyes, modelos y teorías. Tema que desarrollaremos más ampliamente en el apartado siguiente cuando validemos el nivel de teorización en que se encuentra la contabilidad.

Una vez abordado el tema de los conceptos y los axiomas, se hace pertinente indagar sobre la continuidad del proceso científico, alrededor de la estructuración de teorías y leyes, para poder evaluar cómo se ha venido desarrollando la ciencia contable en este rango epistemológico. Según Guerrero (2003) en su artículo "Enfoque semántico de las teorías. estructuralismo y espacio de estados: coincidencias y divergencias", la estructura de una teoría se puede concebir, bajo el enfoque semántico, de la siguiente manera:

“... la tesis central que defiendo es que dentro del enfoque semántico de las teorías los elementos determinantes en la individuación de una teoría son la clase propuesta de modelos teóricos, los modelos de datos y las aserciones empíricas. Pero con las siguientes importantes salvedades.

(1) Un modelo teórico es básicamente una estructura, de modo que la noción de modelo teórico no equivale a la noción semántica, entendida en sentido estricto, como debe ser. (2) Los modelos de datos corresponden a una modelización de la experiencia, a una descripción estructural de la misma... (3) Respecto a la aserción empírica se defiende algo contrario a lo anterior: la forma general de una aserción empírica consiste en que relaciona un modelo de datos con un conjunto de modelos teóricos, pero un análisis estructural de las teorías no se compromete con una forma particular de dicha relación, ya sea de identidad o subsunción u otra" (Guerrero, 2003, 4).

No precisa, el abordaje semántico de las teorías, el elemento tradicional de la construcción de las leyes, pero se deja un marco más amplio bajo la denominación de "modelos teóricos", que presumiblemente las incorpora, ya sea como proposiciones, hipótesis o leyes, cuya precisión se vuelve un poco más difusa en las ciencias sociales. Por ello es interesante traer a colación al estudioso de la ciencia contable García Casella, quien afirma:

"para tener un conocimiento contable científico lo primero es haber reconocido un dominio y un conjunto de fenómenos en ese dominio, y lo segundo es haber ideado una teoría cuyos insumos y productos sean fenómenos en el dominio y cuyos términos puedan describir la realidad subrayable del dominio" (García-Casella, 2001, 122).

Según Popper (1962) las teorías son invenciones humanas o redes creadas para atrapar el mundo, cuya condición es que reflejen la verdad de los hechos; pero advierte que nunca logran ser una representación completa del mundo, así se acerquen estrechamente a esa realidad. En este punto es pertinente formular la siguiente pregunta: ¿Se puede hablar de leyes y teorías definidas y desarrolladas en la ciencia contable? A continuación se procede a buscar una respuesta, pues es muy pertinente establecer el nivel de desarrollo que se ha logrado en el campo contable.

\subsection{El concepto de leyes en la ciencia contable}

Iniciamos la búsqueda de una respuesta al interrogante planteado, revisando la aplicación del concepto de ley científica en la Contabilidad por parte de uno de los pocos exponentes que se han atrevido a 
discurrir sobre este tema, para a partir de allí entablar su análisis crítico. En la construcción de leyes contables, el profesor García-Casella, asume su viabilidad y necesidad, y como metodología escoge el descarte de hipótesis que han sustentado la visión netamente economicista desarrollada por la contabilidad tradicional, inclusive clasificando a Mattessich bajo ese sesgo, para dar cabida a un espectro más amplio que posibilite la inclusión de los fenómenos sociales. Presenta como propuesta, las siguientes leyes, que él considera merecedoras de esa categorización, pues están reflejando ciertas relaciones generalizadoras de los individuos con su sociedad, siguiendo a GarcíaCasella (2001, 14-15):

I. "Las personas y las entidades siempre dedican una parte de sus energías a lograr objetivos no económicos".

II. "Las personas y las organizaciones no pueden decidir con base exclusivamente en datos del pasado y del presente, necesitan datos del futuro".

III. "La contabilidad produce informes contables pero no se limita a ellos en su dominio o universo del discurso".

IV. "Las personas humanas y las organizaciones de personas humanas como no actúan exclusivamente para obtener ganancias necesitan que la contabilidad les provea de informes que midan cumplimiento de objetivos de distinto tipo y no solamente económicos".

V. "La contabilidad es una ciencia autónoma e independiente".

VI. "Los sistemas contables particulares, que producen estados contables son solamente una parte del dominio o universo del discurso contable".

VII. "La contabilidad abarca tareas de control económico como una pequeña parte del dominio o universo del discurso contable".

VIII. "La contabilidad se ocupa de temas que proveen diversas disciplinas, pero por ello no depende de sus respectivas teorías sustentadoras".
IX. "La Contabilidad... estudia todos los fenómenos que ocurren en las organizaciones con la intención de ir brindando información sobre cumplimiento de metas organizacionales no exclusivamente económicas y no exclusivamente en forma cuantitativa".

X. "La contabilidad no está vinculada exclusivamente al principio de dualidad: hay acciones humanas en las organizaciones que no corresponden a ese principio y son materia de la disciplina".

XI. "Aunque la contabilidad tiene relación con la teoría de la medición, es independiente de ella en muchos aspectos de su actuación".

XII. "No es posible expresar las relaciones y mediciones contables exclusivamente en términos monetarios".

XIII. "El dominio o universo del discurso contable abarca hechos y actos del pasado, del presente y del futuro".

Una primera mirada nos hace pensar que las proposiciones planteadas por García Casella (2001), más que leyes son premisas epistemológicas, sobre las cuales se debe construir la ciencia contable. Ello merece un análisis del concepto de ley científica, en el marco de las ciencias sociales, que nos proponemos efectuar a continuación.

Lo primero que debemos discutir es el carácter científico de las leyes sociales, pues los estudiosos del tema reconocen que las características de explicación y predicción que han marcado la pauta en las ciencias físicas, no se ha logrado en las ciencias sociales o por lo menos no de la misma manera, lo cual ha sido objetivo de arduas discusiones en el campo de la epistemología. Las leyes científicas de la naturaleza permiten la predicción de hechos futuros a partir de los presentes, observando las regularidades factuales que se dan en la naturaleza. En las ciencias sociales aún no se ha logrado un nivel de exactitud en la medición de los fenómenos sociales, como lo han logrado las ciencias físicas, por lo que se recurre a aproximaciones en escalas algunas ve- 
ces ordinales, o a mediciones que no han mostrado ser muy confiables, como ocurre con la valoración a costos históricos y la actualmente discutida valoración razonable, lo cual hace muy difícil el ejercicio de uno de los objetivos de cualquier ciencia, como es la predicción, debilitando el corpus y el estatus de la contabilidad como ciencia, siempre y cuando no se abandonen los principios de una ciencia unidireccional, simplificadora, mecanicista y sesgada desde la perspectiva de los intereses de la sociedad en su conjunto.

Las mediciones de las variables implicadas, en muchas ocasiones solo se pueden establecer en escalas ordinales, como cuando en economía se define como ley de la oferta, que a mayores precios, mayores cantidades ofrecidas. Sus relaciones basadas en mediciones concretas, solo tienen validez para situaciones tempo-espaciales específicas, que es lo que se puede plasmar en un modelo. Estos son aproximaciones derivadas de una ley, pero calculadas para condiciones concretas, lo cual significa que los parámetros para esas condiciones no son generalizables. Por lo tanto, en este caso las leyes de oferta y demanda expresan ciertas regularidades entre cantidades y precios, que desde luego son generalizaciones válidas, pero sin que su precisión expresada en mediciones tempo-espaciales concretas, tenga validez universal, sino que se acepta que al bajar a niveles de concreción, las mediciones determinan niveles de precisión de alcance limitado.

Otra diferencia importante es la relación objetividadsubjetividad, que nos lleva al campo de la diferenciación entre explicación y comprensión como modelos metodológicos para conocer la realidad en las ciencias físicas y sociales respectivamente. Mientras que la explicación se considera más propia de las ciencias físicas que son más exactas y se pueden observar desde fuera, la comprensión se ajusta más a las ciencias sociales pues implica entender los fenómenos sociales "desde adentro", esto es, desde la percepción o el conjunto de significados que el sujeto aprehende de la realidad social. Esto es mejor comprendido desde la "complejidad" que parte de unos supuestos diferentes a la ciencia tradicional que se aviene más con el enfoque mecanicista de las ciencias físicas.
Con base en lo anterior podemos llegar a una primera conclusión alrededor del tema de la viabilidad de formular leyes científicas en la ciencia contable como ciencia social que es: Estas leyes deben contemplar, las características analizadas en los párrafos anteriores, es decir deben comprender y explicar las dinámicas patrimoniales, entendidas en su visión más amplia, es decir incluyendo lo social implicado en esas dinámicas. Los dos enfoques, explicativo $e$ interpretativo, no se consideran excluyentes sino más bien complementarios. Aquí es pertinente señalar que la generación de información referente a esas dinámicas patrimoniales es solo una parte de su deber ser como ciencia y muy importante porque permite describir los fenómenos objeto de estudio, pero no suficiente para una verdadera comprensión y explicación de los mismos.

Ello significa que en el proceso de estructuración de una teoría general contable se debe contemplar un conjunto de hipótesis que expliquen las dinámicas patrimoniales bajo cuya consideración se pueden revelar como leyes contables que explicitan ciertas regularidades de esas dinámicas, sin que sean necesariamente relaciones de causa - efecto sino que pueden ser relaciones complejas de doble y múltiples vías pero que permiten comprender e interpretar los fenómenos patrimoniales para facilitar la toma de decisiones y predecir sus posibles consecuencias. Estos aspectos han sido dejados de lado por la corriente anglosajona, que más interesados por definir reglas de estructuración de la información para la mirada específica del propietario del capital descuidaron una mirada más general, comprensiva, interpretativa y explicativa de los fenómenos patrimoniales, que pudieran develar las relaciones sociales y de poder implícitas en un modelo de acumulación de capital y distribución de la riqueza. Estos aspectos se han estudiado más de cerca por las escuelas europeas y latinas, desde los enfoques patrimonialistas y neo-patrimonialistas que claman por una teoría general para la ciencia contable como lo veremos más adelante.

Debemos complementar este análisis epistemológico, retomando el tema de la construcción de las teorías que como lo veíamos anteriormente, tiene la función de integrar en una forma orgánica las premisas, proposiciones, hipótesis y leyes, bajo estruc- 
turas sistémicas que tengan el poder de explicar y comprender, los componentes interrelacionados de la realidad que se estudia, lo cual exige e integra un nivel de complejidad mayor: "La ciencia es el cuerpo de conocimientos sistemáticamente organizados, exactos y verificables de la realidad, que son falibles, pero que tiende a la búsqueda de objetividad" (Romero, 2001, 110).

En este contexto es interesante introducir la diferencia entre ciencia pura y ciencia aplicada pues la primera se orienta más a la generación de conocimiento nuevo independientemente de su utilidad práctica, mientras que la segunda se dedica a encontrar la forma de aplicar los conocimientos desarrollados por la ciencia pura, en la solución de problemas concretos siguiendo el método científico. Ello implica que la ciencia aplicada se orienta a buscar la relación entre los medios y los fines en sus desarrollos aplicativos, investigando métodos, técnicas y herramientas, para lograr los objetivos de adecuar los medios a los fines buscados, todo lo cual se puede y debe sistematizar en cuerpos coherentes de hipótesis instrumentales, partiendo de premisas y estructurando un cuerpo lógico, que en su forma, es similar a la estructuración sistémica de una estructura teórica de una ciencia pura, diferenciándose en que en ésta última el interés es por encontrar explicaciones de causaefecto y adentrarse en el porqué de los fenómenos, de interpretarlos y comprenderlos, mientras que la ciencia aplicada busca la utilidad aplicativa de los conocimientos, generando también conocimiento pero orientado al cómo y el para qué más que a el porqué.

En ese orden de ideas algunos estudiosos ubican a la contabilidad como una ciencia aplicada, como lo definió Mattessich (2002), pero otras corrientes como la interpretativa, la crítica y la Neo-patrimonialista, le dan características no solo de ciencia aplicada, sino de ciencia explicativa, interpretativa y comprensiva de los fenómenos patrimoniales (Ryan et al, 2004).

Queda otra línea científica delimitadora por analizar y es la línea tenue que separa la ciencia aplicada de la técnica como se ve en forma patética en la Contabilidad, entendiendo la primera como el conocimiento utilizado para buscar fines prácticos y la aplicación de los conocimientos científicos, en tanto que la técnica es el conjunto de procesos utilizados dentro de una ciencia aplicada o independientemente de ella, cuando aún no se han esclarecido o establecidos modelos teóricos que respalden tales procedimientos así estos sean útiles.

En ese orden de ideas es como algunos desarrollos disciplinares se inclinan más por la parte técnica de la ciencia aplicada, que por el aspecto científico de la interpretación y explicación de los fenómenos. La técnica puede entonces caracterizarse como un sistema de procedimientos determinados con la mayor precisión posible, transmisibles y objetivos, con la finalidad de producir ciertos resultados considerados útiles (Romero, 2001). Se puede decir que este aspecto es el que se ha priorizado por un estamento profesional y por la praxis del ejercicio profesional, lo que ha mantenido atrapado en este estrecho marco el desarrollo de la disciplina contable, interesada en la realización de ciertos procedimientos o productos útiles para fines específicos pero apartándose de esa manera del desarrollo científico, que se ha asumido en forma tímida por un sector de académicos, que han aportado nuevos elementos para la concepción científica de la profesión, caracterizada por la búsqueda de la verdad y la generación de conocimiento.

Se entiende que la ciencia es explicativa de los hechos y tiende a decir por qué son de esa manera, mientras que la técnica se interesa por cómo hacer las cosas para obtener un fin eficazmente, el cual se da por conocido, sin preocuparse por el conocer o saber por qué se persigue ese fin y no otro diferente. Ello ha originado que "las dificultades que existen para distinguir entre la ciencia y la técnica, teniendo en cuenta que la contabilidad es una disciplina que por su lenguaje y conocimientos es común a ambos campos del conocimiento y se influyen mutuamente (la técnica fomenta la ciencia y los nuevos conocimientos científicos posibilitan nueva técnica)" (Romero 2001, 110).

Para Bunge (1989), las teorías se pueden considerar científicas si sistematizan el conocimiento explicando las regularidades empíricas descubiertas y los hechos analizados, a través de proposiciones que hacen explícitas sus relaciones lógicas y factuales, incremen- 
tando así el conocimiento con nuevas proposiciones y estableciendo el control entre las hipótesis derivadas del cuerpo existente. Ello significa que la ciencia contable debe ir más allá de establecer reglas de construcción de sistemas de información para dar cuenta y descripción de los hechos económicos, para pasar a buscar teorías explicativas, comprensivas e interpretativas del porqué de esos fenómenos y del para qué y para quién de sus resultados. Es decir se debe superar el enfoque de la regulación contable que se orienta a la normatización y normalización de la teneduría de libros, para asumir la comprensión y explicación de los fenómenos que allí se recogen y representan. Esto último permite una participación más activa del Contador en los procesos de toma de decisiones y en la misma definición de la normatividad contable y no ser un ente pasivo que solo aplica normas definidas por otros y muchas veces para contextos que no se adecúan a las realidades, en que él se desenvuelve. Sin embargo esta tarea se ha dejado para los investigadores académicos, lo que ha hecho que se separe el ejercicio pragmático de la profesión del desarrollo teórico de la disciplina generando un divorcio, que le está costando ver atrapado su desarrollo.

Una vez efectuada esa revisión panorámica desde la epistemología, se vuelve pertinente contrastar cuál es el nivel de teorización que ha alcanzado la ciencia contable, para a partir de allí poder establecer los caminos que se deben seguir para lograr la consolidación de una teoría general contable. A continuación abordamos el primer aspecto, para abordar luego el segundo tópico.

\section{4. ¿En qué nivel de teorización se en- cuentra la contabilidad?}

Para determinar la viabilidad de una teoría general contable es necesario evaluar el estado del arte de su desarrollo, lo que se pretende abocar en este apartado a través de una mirada panorámica y sintética de los avances que se han logrado en la construcción de la ciencia contable.

Para lograr esa mirada panorámica desde la perspectiva de la consolidación científica de la contabilidad, se seguirá el esquema planteado por Vásquez \& Bongianino (2008):
- Período empírico.

- Nacimiento y formación de la partida doble.

- Extensión y aplicación de la partida doble

- Período científico.

El primer período es el desarrollo del esfuerzo humano por plasmar a través de diversos tipos de representación las transacciones económicas, pero sin ninguna pretensión de sistematización, es decir sin establecer un principio de coordinación e integración de dichas anotaciones, lo que luego se convirtió en un registro racionalizado de todas las transacciones ordenadas cronológicamente, lo que se constituyó en la "partida simple". Este período avanza hasta inicios del siglo XIII.

El segundo periodo avanza hasta finales del siglo $\mathrm{XV}$, cuando se inicia el auge del capital mercantil, lo que exige concebir la riqueza no solo como acumulación de bienes sino como acumulación de capital productivo, jugando éste un papel fundamental en el crecimiento económico a través de su reproducción simple y ampliada. Esto exige una racionalización de la información que requiere la consolidación de sistemas ordenados y organizados de registro y control, lo cual da origen a la sistematización por partida doble. Es decir, se empiezan a sentar las bases de una teorización contable por que es necesario establecer las relaciones que se dan entre los diferentes componentes del capital y ello se va a reflejar en los esquemas de representación contable de la riqueza.

Esto exige una interpretación diferente a la que hasta ahora se ha dado a la contabilidad como sistema de medición y representación, pues éste no es sino una de sus funciones, resultado de la manera como los pensadores contables leyeron $e$ interpretaron las relaciones implícitas en la generación, apropiación y distribución de la riqueza, concepto social por naturaleza. Así surge la representación de los diferentes tipos y sistemas de cuentas, constituyéndose en el gran avance de la contabilidad en su proceso de estructuración como ciencia aplicada. La pregunta que cabría hacerse es si se continuó con la teorización sobre esas relaciones representadas, o simplemente se 
dieron por sentadas sin mayor explicación y se prefirió teorizar sobre las formas de representación bajo una lógica de formalización que sigue toda ciencia una vez que ha consolidado una serie de leyes explicativas o interpretativas de la realidad objeto de estudio que para nuestro caso es la riqueza como fenómeno social, aspecto que parece haberse saltado en la estructuración científica de la contabilidad.

El tercer período de extensión y aplicación de la partida doble, sigue profundizando en la teorización alrededor de la partida doble, estableciendo sus principios y generándose el estudio de nuevos conceptos alrededor de la riqueza como la valoración, el análisis de resultados, la separación entre propietario y empresa, el balance de comprobación, las previsiones económicas (presupuestos), la naturaleza de las cuentas de capital y de pérdidas y ganancias, los asientos complejos, asientos de regularización y cierre, el arte de los negocios, las tareas de caja, el cálculo económico, entre otros. Mención especial merece aquí la teorización sobre las cuentas, avance logrado en los siglos XVII y XVIII. Se proponen distintos esquemas de clasificación de las cuentas, siguiendo esta misma filosofía de considerar el estudio de las cuentas como la esencia de la contabilidad.

El período científico se empieza a consolidar con el inicio de la revolución industrial en 1760 que es el inicio del capitalismo industrial propiamente dicho. Es el momento de empezarse a preocupar por cuestiones diferentes al mecanismo de las cuentas y se comienza a profundizar en temas más complejos que permiten hablar de la elaboración de un cuerpo de teoría contable. Así Francesco Villa a mediados del siglo XIX, busca la integración entre los principios de la administración de empresas con la práctica contable y diferencia entre la teneduría de libros y la contabilidad que busca solucionar problemas económicos y administrativos de las empresas.

Podríamos decir que este período marca el actual desarrollo de una teorización contable, estableciendo principios ya no solo sobre la representación sino también sobre la esencia de los fenómenos de la riqueza, tal como lo hace Masi (1962): -Establece la diferencia entre la propiedad y su administración, -define el principio de la dualidad que establece que no hay deudor sin acreedor, -determina que el patrimonio se afecta por los aumentos o disminuciones provenientes de las pérdidas y ganancias, buscando el origen de las dinámicas patrimoniales.

También aparece la "Teoría de la Entidad", que busca clarificar las relaciones jurídicas entre la entidad y los terceros ajenos a la misma. Podríamos decir que aquí se enfatiza en las relaciones entre lo jurídico y lo contable. Lo problemático es que algunos desarrollos anglosajones se han estancado en esta perspectiva, influenciando el desarrollo de los países latinoamericanos que hasta ahora han empezado a buscar caminos diferentes de desarrollo de la ciencia contable.

Sin embargo se han ido desenvolviendo paralelamente otros enfoques que han terminado dándole un giro a la teorización contable, centrados en el valor económico representado en las cuentas, que termina por considerar a la contabilidad como la ciencia del control económico lo cual acerca más la teoría hacia la explicación de la riqueza y de los factores que intervienen en ella. De allí se derivan las nuevas corrientes que propenden más por establecer un modelo de lo que la contabilidad debe ser entrando en el terreno de las teorías normativas, que de alguna manera se aproximan al enfoque social de la contabilidad que había sido dejado de lado.

En ese orden de desarrollo se establece como foco de análisis del movimiento de la riqueza y sus explicaciones, la administración de los entes, que se conoce como la economía hacendal, logrando un desarrollo importante en Alemania a través de la escuela normativa que establece una única fuente del conocimiento en las normas y valores de validez universal, lo cual se podría considerar como un primer paso hacia establecer una teoría general de la contabilidad. De allí se deriva el patrimonialismo cuyo máximo exponente es Masi (1962), quien señala el patrimonio como el objeto a estudiar por parte de la Contabilidad. A ello se agrega la teoría causal expuesta por Leo Gomberg (citado por Vásquez et al., 2008) quien establece como ley general de la contabilidad el equilibrio entre causa y efecto, siendo las causas la financiación u origen y los efectos los activos producto de esa financiación. En esa línea de pensamiento trabaja Yuri Ijiri (1975) quien relaciona 
la partida doble con la relación causal entre aumentos y disminuciones de los recursos, como parte del estudio de la dinámica de las masas patrimoniales y que incorpora la Contabilidad multidimensional para incluir cantidades no monetarias.

Este enfoque luego será retomado por Lopés de Sa (2007) con su enfoque neo-patrimonialista que estudiaremos en detalle más adelante. Se podría decir que se culmina el planteamiento de este enfoque con la Contabilidad Social, que ya contempla aspectos sociales aunque todavía en la esfera de lo económico generando un balance social relacionado con los recursos humanos y medioambientales. La pregunta que cabe hacerse en este punto es si es suficiente este alcance dado a la Contabilidad Social o si ésta debe ir más allá buscando las explicaciones desde lo social de las dinámicas patrimoniales, considerando que no solo se debe hablar de patrimonio económico sino también de otras clases de patrimonios, recomponiendo en un sentido amplio lo Social que debe ser aprehendido desde la Contabilidad como Ciencia y cómo esta apertura debe ser comprendida y estudiada desde una teoría general contable.

Del anterior recorrido se puede concluir que el esfuerzo por generar una teorización contable ha logrado un avance estructural importante, alrededor de lo cual se puede consolidar una teoría general de la contabilidad que integre los diferentes componentes del objeto de estudio que hasta ahora se han venido estudiando en estancos separados. Su eje se ha ido identificando con el fenómeno patrimonial gestionado por las unidades organizacionales en el marco del entramado social con sus implicaciones de relaciones sociales de poder que luchan por la distribución de la riqueza. Esta se genera, transforma y distribuye a través de las dinámicas patrimoniales, que se deben estudiar en diferentes niveles: micro, meso y macro; pero sus principios se deben unificar a partir del estudio de las relaciones que se establecen al interior de cada nivel y entre los niveles, que es lo que consideramos aún falta para acabar de estructurar la teoría general.

En lo que de igual manera se ha avanzado, a partir de los requisitos epistemológicos para considerar a una teoría como científica, es en el carácter explicativo, comprensivo e interpretativo de cierto tipo de leyes que están en proceso de formulación y formalización a un mayor nivel de profundidad. En buena medida todo ello se ha ido estructurando y consolidando en dos modelos teóricos, que bien se pueden integrar y complementar para lograr un enfoque integral muy sólido, con todas las características de una teoría general: Se trata de los modelos desarrollados por Richard Mattessich y por Lopes de Sá, que se entrarán a analizar a continuación. Sin embargo antes, queremos traer las conclusiones a las que llega el profesor Eduardo Alejandro Ibáñez, Doctor en Filosofía y Profesor de la Universidad Católica de Santa Fe, de la Universidad Nacional del Litoral y de la Universidad Tecnológica Nacional, al indagar sobre el estatus científico de la contabilidad, para delinear el camino a seguir para consolidar la estructura científica de la misma:

"Así como la Contabilidad evolucionó de un mero arte de registración contable fundado en la práctica, a una técnica normada, considero posible que evolucione del estado actual de protociencia a ciencia estricta, bajo las siguientes condiciones: a) En la medida que la Contabilidad unifique los criterios para reunir información contable, es decir, homologue su normativa de registración a nivel internacional; b) en la medida que reconvierta las diferentes Teorías Generales Contables existentes en una sola teoría que goce de consenso y unanimidad entre los miembros de la comunidad científica de contadores, axiomatizando $y$ formalizando dicha Teoría General única; y c) en la medida que elabore modelos contables de modo exhaustivo (completos, no parciales); y d) en la medida que, como producto de la formulación de una Teoría General Contable unificada, elabore leyes generales que posean capacidad explicativa y predictiva" (Ibáñez, 2010, 13).

Ahora se efectuará una rápida revisión de los dos modelos mencionados. 


\section{Dos enfoques actuales de la teoría general contable}

Una vez analizado el desarrollo científico de la Contabilidad, se ha llegado al punto donde es necesaria la formalización matemática de la teoría contable, pero como hemos visto hasta ahora, también se da la exigencia de unificar bajo una teoría integradora los diferentes enfoques que han dado respuestas parciales y orientados más hacia la representación que hacia la explicación e interpretación de los fenómenos objeto de estudio. Precisamente la matemática facilita este camino, pero también aquí se plantean dos alternativas: Una establece que la Contabilidad se debe incluir dentro de las ciencias formales como parte de la matemática y la otra procura exponer las teorías contables utilizando el lenguaje matemático. En esos desarrollos han contribuido dos aspectos claves: por un lado el interés del análisis del comportamiento de los individuos frente a los asuntos económicos, y derivados de él, la concepción comunicacional de la contabilidad, aspecto que empieza a humanizar la teorización contable, pero que no trasciende hasta el análisis de los comportamientos sociales y sus relaciones intrínsecas que le den fundamento a los movimientos de las masas patrimoniales vistos como fenómenos sociales. De otra parte se replantea el objetivo de la Contabilidad, para incluir esos aspectos sociales, como la responsabilidad social y todo lo que ello implica, ampliándose el marco para la teoría general contable.

Bajo ese derrotero es que se dan intentos de formalizar una teoría general contable, que pretendemos evaluar como una primera aproximación al estado del arte en este camino y para ello nos concentraremos en dos enfoques que resultan ser representativos y que han hecho aportes fundamentales en este frente a la disciplina contable: el enfoque formalizador de Mattessich y el enfoque Neo-patrimonialista de Lópes de Sá.

\subsection{El enfoque formalizador de Mattessich}

Iniciamos con el estudio de este enfoque que ha sido muy bien ponderado por los estudiosos del tema y por considerarse a Mattessich, como el máximo exponente de la teorización contable. Es interesante iniciar esta presentación indicando que la disección entre micro-contabilidad y macro-contabilidad, es una forma de entender los dos tipos de intereses que no se han logrado reconciliar entre la contabilidad de los entes económicos individuales y la contabilidad social representada en uno de sus aspectos, en el estudio de los grandes agregados económicos, que hasta ahora se le ha cedido a la macroeconomía, sin considerar otros tópicos de tipo social que también debe abocar la contabilidad como ciencia. Pero tratando de conciliar la micro con la macrocontabilidad, es cuando aparece el esfuerzo pionero de Mattessich de coordinar las dos teorías bajo un enfoque generalizante, aunque en opinión de Pinilla (1976), solo lo haya logrado parcialmente pues su orientación está más cargada hacia la contabilidad de los entes que hacia la macro-contabilidad.

\subsection{El enfoque crítico propuesto por Pinilla}

En respuesta a sus propios planteamientos críticos a los alcances logrados por Mattessich, Pinilla propone un programa alternativo de investigación para encontrar las bases suficientes y necesarias para establecer la unicidad de la teoría de la contabilidad. Operacionaliza el objeto de estudio como el proceso circulatorio de la renta y/o riqueza de una entidad, solucionando la escisión entre lo micro y lo macro, al contemplar el proceso de renovación de la riqueza, que se refleja en flujos de doble vía entre los productos y servicios y la renta generada a partir de ellos. Es la focalización en los flujos lo que permite integrar el análisis desde lo micro hacia lo macro, pues ellos mismos explican cómo fluye la riqueza entre los integrantes constituidos por diferentes tipos de entes que conforman la sociedad: las empresas, los consumidores, el Estado, el resto del mundo, el sector financiero, entre otros.

La tesis fundamental de Pinilla (1976) es que el propósito que se siga debe orientar la construcción del modelo, independientemente del método seguido. Así por ejemplo el estado de resultados se puede utilizar tanto a nivel micro como a nivel macro para estudiar la producción a nivel de empresa o a nivel del país. Las mismas cuentas pueden servir para estudiar el bienestar económico de la sociedad, o la productividad y rentabilidad del ente. De la misma 
manera el estudio de los ciclos macroeconómicos se debe poder lograr partiendo del ciclo económico de la empresa, integrando hipótesis complementarias que relacionen las cuentas del plan contable de tal manera que se expresen en ecuaciones de comportamiento que expliquen o describan las funciones macroeconómicas como la renta nacional, la producción nacional, etc. Este es un ejercicio que se puede denominar Contamétrico, pues implica la manipulación matemática de las cuentas, instrumento eminentemente contable; lo cual le daría el carácter diferencial frente a un ejercicio de tipo econométrico.

De esta manera se ligaría el estudio de los precios, el ahorro, la inversión a nivel macro con los procesos de formación de la renta, la óptima asignación de recursos y la maximización del resultado desde el nivel micro. En síntesis la generalización en este caso para representar, comprender, interpretar y explicar los fenómenos patrimoniales solo se diferenciarían por los objetivos que tienen los entes individuales frente a los objetivos de la sociedad en su conjunto, que de alguna manera se deben estudiar en forma conjunta para entender sus complementariedades, contradicciones, confluencias y así entender la lógica formal de dichos procesos. Este sería uno de los fundamentos que oriente la estructuración de una teoría general contable, visto desde esta perspectiva, que sigue siendo parcial, pero de esa manera se empieza a tejer la red, como lo establece el estudio científico desde la complejidad.

Este autor desarrolla un enfoque axiomático, que es interesante, pues inicia con axiomas, que se consideran una verdad general acerca del objeto de estudio o de algunos de sus componentes, que es evidente y por lo tanto no requiere demostración, sino sólo el consenso de la comunidad científica pertinente. Podrían requerirse definiciones para precisar el axioma. Del axioma se derivan postulados que son características de lo enunciado en el axioma, y que de igual manera se consideran una verdad que es consensuada entre los integrantes de la comunidad científica y que no requiere demostración. A partir de ese conjunto de postulados se puede derivar un teorema, que expresa alguna identidad o relación derivada lógicamente de los postulados y del axioma.
A manera de ejemplo traemos a colación una parte básica de la estructura propuesta por el autor:

- Axioma de entidad contable: "Existe una entidad contable cuya renta y/o riqueza es analizada".

- Definición de entidad contable: "Una entidad contable es cualquier ente físico, jurídico (de interés público o privado), región, nación, etc. Que ejerce actividad económica".

- Primer postulado de entidad contable: "El análisis de la renta y de la riqueza es posible aplicarlo a subconjuntos y a super-conjuntos de entidades contables".

- Teorema I: "La renta y riqueza agregada de los subconjuntos de la entidad contable, es igual a la renta y riqueza de dicha entidad".

Los otros axiomas propuestos son los de causalidad, de los flujos circulatorios, del proceso circulatorio, de medición, de valoración, de los intervalos temporales y de la información. Alrededor de estos axiomas es que se propone construir la teoría general, lo cual coincide con los esfuerzos metodológicos que se han hecho alrededor del propósito de formalizar una teoría general, partiendo de unos axiomas fundamentales y a partir de allí derivar el resto de la estructura científica de la contabilidad.

El autor logra centrar la estructura alrededor del concepto de los flujos circulatorios de la riqueza, buscando con ello integrar y unificar los fundamentos del estudio de la micro-contabilidad y la macrocontabilidad, y con ello, de la ciencia contable. Detrás de ese esfuerzo está el supuesto de que la microcontabilidad asume el estudio particular e individual desde la perspectiva de la empresa, lo cual no tiene discusión; y que la macro-contabilidad aborda todo el tema social, lo cual es cuestionable, pues su eje sigue siendo lo puramente económico así se haga desde los grandes agregados nacionales.

Ello nos conduce a la conclusión de que de esa manera la solución sigue siendo parcial pues lo que se pretende es integrar una teoría general que incluya 
todos los componentes que debe abordar la ciencia contable, pero aporta ciertamente al diseño metodológico de la construcción de dicha teoría general apuntando a la forma de estructurar los fundamentos bajo un esquema sólido de axiomatización, derivando de allí elementos claves en la organización de tales fundamentos. Tal vez lo que sí valga la pena, es discutir en torno a este último punto, si es suficiente llegar al planteamiento de los teoremas como fundantes de toda la explicación e interpretación de los fenómenos de la riqueza, o si es necesario avanzar precisamente en este aspecto, para trascender la mera descripción de los fenómenos donde parece que estuviera atrapada la teorización contable.

Para responder esta inquietud es necesario retornar al análisis del enfoque de Mattessich, del que nos apartamos temporalmente para abrir un interesante paréntesis, destinado a una crítica fundamentada que nos permite comprender mejor o contextualizar todo el entramado teórico desarrollado por Mattessich. Empecemos por afirmar que Mattessich considera:

"la contabilidad una ciencia aplicada, que persigue un fin práctico como es, en medir los factores de riqueza en una entidad económica. Para ser más puntual la diferencia entre ciencia pura y ciencia aplicada radica en que mientras la primera busca la relación causa-efecto, la segunda se orienta a la relación fines-medios" (Mattessich, 1995 86).

Un importante aporte de Mattessich (1995) es la distinción entre el enfoque positivista y el enfoque normativo en la Contabilidad que establece, partiendo de la premisa de que las ciencias puras son las encargadas de dar explicaciones de los fenómenos buscando las relaciones de causa-efecto (que él caracteriza como ciencia positiva) a diferencia de las ciencias aplicadas que se preocupan más por las relaciones fines-medios ubicando a la Contabilidad en esta última categoría. Ello conlleva a determinar que el enfoque de la Contabilidad se debe preocupar por establecer reglas de construcción de sistemas contables a partir de los objetivos que se busquen para satisfacer necesidades de información financiera de diferentes tipos de usuarios. Aquí cabría cuestionarse si este es el máximo alcance que se le puede asignar a la Contabilidad como Ciencia, pues de allí dependerá el enfoque y la estructura del conjunto de los axiomas requeridos para fundamentar la teoría general que se proponga, pues así se estaría fijando su delimitación y alcance. Es pertinente considerar el caso de la ciencia económica que acepta dos grandes divisiones: la economía positiva y la economía normativa incluyendo la primera a la economía descriptiva y a la teoría económica (Cruz, 1999, citado en Mejía, 2004)

A pesar de que Mattessich (1995) define a la Contabilidad como ciencia de carácter empírico, social y positivo-normativo, estamos de acuerdo con la crítica del profesor Pinilla, analizada anteriormente, en el sentido del sesgo que termina imprimiendo el modelo de Mattessich privilegiando lo empírico-aplicativo, lo normativo y lo individual-empresarial, como lo analizaremos a continuación.

Para el caso es muy importante reseñar la estructura fundamental que propone Matessich (1995): Unidad monetaria, unidad de tiempo, estructura, dualidad, acumulación, objetos económicos, unidad de medida estable, agentes económicos, entes, transacciones económicas, valuación, realización, clasificación, ingreso de datos, duración o periodo, consolidación, significatividad, asignación o imputación. Como se observa el enfoque prioritario es la medición de la riqueza desde el aspecto económico, centrado en las unidades sociales.

En principio, la intencionalidad de Mattessich (1995) es construir una teoría general que sirva de base a todos los sistemas contables, por lo que su entramado se arma alrededor de un sistema axiomático, que termina integrando con la ayuda de los fundamentos matemáticos de las matrices. Se colige de ello que lo prioritario sigue siendo la aplicación de conocimientos más que la generación de conocimientos que expliquen las realidades, por lo que utiliza hipótesis instrumentales adecuadas a los fines específicos. Sin embargo plantea como una de las tareas básicas de la Contabilidad la valoración del activo del capital y de la renta con el fin último de asignar correctamente los recursos, lo cual no profundiza desde la teorización para explicar las dinámicas patrimoniales, pero si enfatiza en el fin práctico de la medición de los factores de la riqueza. 
Define como criterio de validación de las proposiciones la contrastación de efectividad de los medios para alcanzar los fines, lo que comprueba su sesgo hacia lo aplicativo-normativo. Ello no implica que se deje de plantear temas de carácter positivista, según la misma denominación que él usa, pero que no necesariamente compartimos, pues no toda la esfera de la ciencia pura, o no aplicada, que se encarga de teorizar o explicar tiene un marco positivista, pues existen otros enfoques tanto explicativos como interpretativos, que están siendo abordados por la corriente crítica de las ciencias sociales, donde la investigación cualitativa ha ganado un espacio importante, alejándose de la corriente positivista que se enmarca más en un enfoque cuantitativo. Entre los planteamientos con características de ciencia explicativa, Mattessich resalta los tópicos de la valoración que mencionamos anteriormente y también los que reflejan su orientación marcadamente hacia lo económico, aportando menos elementos desde la perspectiva de lo social, como lo planteaba el crítico profesor Pinilla quien finalmente tampoco logra escapar a esta tendencia con su planteamiento de integrar la micro-contabilidad con la macro-contabilidad. De cualquier manera no se puede negar el gran aporte de Mattessich a la consolidación de la ciencia contable al formalizar mediante la axiomatización los principios, hipótesis y estructuras teóricas, que así alcanza un nivel de rigor científico que se debe aprovechar para ampliar el marco de estudio y acción de la ciencia contable.

\subsection{El enfoque Neo-patrimonialista de Lópes de Sá}

Lopes de Sá (1992) en el Neo-patrimonialismo critica la tradicional representación contable a través de la partida doble, pues en su concepto, ésta refleja la fuente de los recursos y los efectos de esa operación como contrapartida, pero no permite mostrar muchos aspectos dimensionales y correlaciones importantes, con lo cual se pierde la posibilidad de explicar e interpretar los fenómenos patrimoniales a un nivel de profundidad requerido por el restablecimiento de la esencia del fenómeno inmerso en el comportamiento patrimonial. Ello le lleva a comprender y estudiar el hecho económico que produce una serie de acontecimientos simultáneos con finalidades múltiples, estableciendo relaciones de causalidad en múltiples vías, reconociendo la complejidad social inmersa en esas relaciones.

A partir de allí enfoca el análisis de las dinámicas patrimoniales entendidas como las formas que asume la creación de esa riqueza, su distribución, su acumulación, su circulación y las formas como reflejan las relaciones sociales de poder, con lo cual identifica la riqueza por las diferentes funciones que asume en esos procesos, lo cual para la contabilidad significa reconocer los tipos de relación entre medios y necesidades. Esto es lo que él define como funciones patrimoniales, entendidas como la forma de estudiar la adecuación de los medios para lograr ciertos resultado deseados, rescatando el análisis de las relaciones que se establecen entre diferentes alternativas de combinación de medios y los impactos que se alcanzan, permitiendo que la contabilidad como ciencia entre a desentrañar, comprender y explicar los fenómenos objeto de estudio, siendo éstos las dinámicas patrimoniales. Entre esas explicaciones es importante reconocer la productividad de los diferentes factores involucrados, hasta integrar la productividad global y la forma como se reconoce el aporte de cada factor a esa generación, permitiendo analizar los desequilibrios implícitos en esos procesos sociales.

Sobre la base de los anteriores planteamientos el desarrollo teórico del neo-patrimonialismo reconoce ocho tipos de funciones: las capacidades de Pagar (liquidez), obtener ganancias (resultabilidad), mantener el equilibrio (estabilidad), tener vitalidad (economicidad), protegerse contra los riesgos (invulnerabilidad), ser eficientes o producir adecuadas utilidades (productividad), dimensionarse de forma competente (elasticidad), contribuir como agente para el entorno (sociabilidad) (Nepomuceno, 2008). Así cuando ocurre una venta se afectan esas ocho dimensiones: la liquidez, los resultados, los riesgos, los niveles de pérdidas, la dimensión del patrimonio, la estructura patrimonial, las condiciones de supervivencia y la sociabilidad. Se observa que esta definición de funciones implica un paso adelante hacia el establecimiento de las relaciones de multicausalidad y de efectos múltiples a partir de las decisiones económicas de las unidades sociales que cumplen esa condición de ser generatrices y organizadoras del fe- 
nómeno social de la producción, distribución y consumo de los bienes y servicios, con el fin de satisfacer necesidades de los seres humanos que conforman la sociedad.

Lópes de Sá reformula el concepto de patrimonio como acumulación de riqueza para ubicarlo bajo una perspectiva dinámica, lo que implica explicar las causas y efectos de su origen y desarrollo y lo correlativo a su finalidad: El conjunto de medios adecuados para satisfacer la necesidades hacendales, lo cual conlleva elementos de la ciencia normativa, que incluye además de las relaciones de causa-efecto, las relaciones entre fines-medio. Todo ello el autor lo denomina como los fundamentos lógicos de la teoría de las funciones sistemáticas del patrimonio hacendal, lo que de por sí es diciente de su preocupación por establecer las bases científicas de la teoría contable: "Los motivos que nos han llevado a elaborar la presente teoría fueron los de ofrecer una Estructura Epistemológica del conocimiento contable en un cuerpo de doctrina de acuerdo con la evolución científica y tecnológica de nuestro siglo" (Lópes de Sá, 1992, 13)

En opinión del profesor Luiz Fernando Coelho da Rocha (Brasil), Abogado, miembro de la Asociación Científica Internacional Neo-patrimonialista, ACIN y Miembro del $8^{\circ}$ período de ciencias contables, del equipo de la ENM-Auditores, "el rigor epistemológico de esta doctrina contable contemporánea sigue la secuencia de observar, percibir, conceptuar, formular axiomas y teoremas y, como consecuencia lógica, construir una verdadera teoría de tenor holístico y heurístico (hecho que no siempre ha acaecido con otros segmentos doctrinarios)" (Coelho, 2004, 130). Reconoce este autor, que aunque Richard Mattessich se aproximó al enfoque axiomático, solo el neo-patrimonialismo lo adoptó de forma organizada y sistemática, es decir, sujetándose a los rigores de la filosofía científica, llegando inclusive a generar una "teoría general del fenómeno patrimonial", partiendo de una estructura axiomática totalmente desarrollada alrededor de los modelos de comportamiento de la riqueza de las empresas y las instituciones. Es decir existe un paralelismo entre el esquema axiomático de Mattessich y el de López de Sá, con la ventaja de este último, de buscar explicaciones del fenómeno patrimonial a través de la definición de las funciones explicadas anteriormente.

Como se puede deducir el esquema de López de Sá, da una respuesta a la estructuración científica avanzando hacia la explicación, comprensión e interpretación de las dinámicas patrimoniales. Sin embargo consideramos que todavía su mayor esfuerzo se concentra en lo económico. Es por ello que en este artículo proponemos complementar y ampliar la estructura de las funciones agrupándolas en tres categorías, que recogen las visiones no solo de lo económico (primera categoría), sino rescatando el profundo contenido humano de la disciplina (segunda categoría de funciones alrededor del desarrollo humano y su máxima expresión el conocimiento) y el hondo sentido social de su responsabilidad (tercera categoría). De igual manera concebimos que para lograr integrar una teoría general contable se debe recurrir a la matematización a través de la representación de funciones matemáticas que se integren sistémicamente en sistemas y subsistemas funcionales, bajo la modelización matemática, como expresión científica de las relaciones, interrelaciones y reciprocidades, que conforman lo que denominamos "modelos contamétricos", que buscan comprender y explicar las dinámicas patrimoniales. Es decir a partir de los modelos de Mattessich y de López de Sá, se propone integrar fortalezas de los dos modelos y reforzar los componentes humanos y sociales de la disciplina contable, enmarcados en un esquema de estructuración científica siguiendo el enfoque axiomatizador de estos dos eminentes científicos de la Contabilidad y proponiendo líneas de desarrollo sobre todo en el fortalecimiento de teorías derivadas de un esquema general, como nos atrevemos a sugerir y proponer para la discusión, definiendo un esquema posible de dicha estructura, que se puede convertir en un Programa de Investigación para la disciplina. A continuación se presenta tal propuesta:

\section{Hacia una propuesta de estructuración de la teoría general contable}

La siguiente propuesta busca dar respuesta a la problemática planteada en los anteriores apartados y solo persigue establecer un diálogo sobre la misma, entre los estudiosos del tema de la estructuración de 
una teoría general contable que como lo decíamos se puede convertir en un programa de investigación para la disciplina. Abordaremos la propuesta desde tres tópicos: definición de los componentes fundamentales de una teoría general contable, la evolución hacia una teoría general contable y las alternativas de desarrollo de la teoría general contable.

\subsection{Definición de los componentes fundamen- tales de una teoría general contable}

Empezamos por proponer que se establezca un primer nivel de premisas orientado a definir el objeto y estructura de la ciencia contable (en razón a su actual discusión, no resuelta del todo) y un segundo nivel orientado a los diferentes componentes del método de la contabilidad como ciencia. En la primera categoría proponemos a manera de discusión las siguientes premisas básicas:

- El objeto de la ciencia contable es el estudio del movimiento de las masas patrimoniales, definiendo el patrimonio como equivalente a la riqueza expresada en tres fuentes: patrimonio económico, patrimonio socio-cultural y patrimonio humano. Es decir la comprensión, entendimiento y explicación de esos movimientos es la razón de ser de la ciencia contable.

- La anterior premisa se sustenta en otra propuesta por García-Casella (2001, 14-15): Las persona y las entidades siempre dedican una parte de sus energías a lograr objetivos no económicos (citado por Mejía et al., 2005). Es decir los objetivos no son solo económicos sino también sociales y deben ser cubiertos por la ciencia contable.

- El objeto de la ciencia contable desde la perspectiva económica debe contemplar la producción, la distribución y el consumo, examinando y dando cuenta de las relaciones sociales inmersas en esas funciones económicas y sus impactos en los movimientos de las masas patrimoniales.

- Las mediciones deben utilizar diferentes unidades de medición: cuantitativas y cualitativas, económicas y no económicas, combinadas en indicadores de composición mixta, de tal manera que se amplíe el modelo multidimensional de la ciencia contable.

- La información alrededor de las tres fuentes de la riqueza y sus mutuas relaciones debe integrar datos que reflejen el pasado, el presente y el futuro de sus movimientos, respondiendo a una dinámica compleja de los fenómenos sociales y económicos estudiados.

- La mirada explicativa e interpretativa de los fenómenos patrimoniales en su sentido amplio se debe sustentar en el enfoque multidisciplinar, interdisciplinar y transdisciplinar alrededor de la riqueza.

- La contabilidad como ciencia se debe integrar a las ciencias de la vida y su enfoque sistémico se debe apoyar en el paradigma de la complejidad.

- La Ciencia contable debe describir y determinar los diferentes niveles de la vida en su expresión patrimonial en el sentido amplio, cada uno de los cuales deben ser entendidos, interpretados y explicados no solo al interior de cada nivel, sino en su proceso de emergencia, transformación y mutuas interacciones entre esos niveles.

- La Teoría General de la Contabilidad debe abarcar la Contabilidad Financiera, la Contabilidad Gerencial, la Contabilidad Gubernamental, la Contabilidad Nacional o Económica y la Contabilidad Social (García-Casella, 2008)

En el segundo nivel, proponemos los componentes del método de la siguiente manera, a cada uno de los cuales corresponden premisas básicas derivadas del primer nivel: captación, simbolización, medida, valoración, representación, coordinación, agregación, análisis e interpretación. En este artículo no se pretende entrar al detalle del conjunto total de premisas básicas, sino de ofrecer una perspectiva amplia de la estructura general de la teoría contable, por lo que sólo se propondrá una premisa básica y amplia sobre cada uno de los mencionados componentes a 
partir de las cuales se deben derivar otras premisas que completen el espectro de los fundamentos de la ciencia contable, lo cual se debe convertir en un programa de investigación abierto a todos los estudiosos de la ciencia contable. A continuación se establecen esas premisas correspondientes a cada uno de los componentes:

- Captación: La captación de los fenómenos económicos y sociales del patrimonio o de la riqueza debe contemplar las perspectivas de los diferentes usuarios de la información y establecer los objetivos para los que se hace dicha captación.

- Simbolización: "La Contabilidad podría entenderse como "un subrogado genérico de primer orden, integrado por un conjunto de subrogados de órdenes inferiores, susceptibles de aplicación en la transmisión de la imagen de principales cuya estructura resulte compatible con los principios generales de su metodología científica" (Requena, 1977). Las cuentas, por su parte, no son más que subrogados de orden inferior, de que se vale la Contabilidad para la transmisión de esa imagen" (Gómez, 2009, 17).

- Medida: La contametría debe ser el eje estructurante del modelo de medición contable, integrando la información financiera con la no financiera, de tipo cuantitativa y cualitativa, bajo una misma lógica estructural. Así podrá generar reportes más comprensivos sobre el patrimonio, buscar las interrelaciones de sus diferentes componentes y medir sus impactos desde la perspectiva no solo individual sino social, a través de todo el esquema científico de axiomas, premisas, hipótesis, teoremas, silogismos hipotético-deductivos, leyes, teorías, modelos, que expliquen el movimiento de las masas patrimoniales y sus impactos económicos y sociales (Ortiz, 2012).

- Valoración: El problema de valoración debe girar no solo alrededor del valor económico, sobre lo cual la ciencia contable debe expresar sus fundamentos, sino también sobre el valor de lo social, sobre lo cual también debe establecer sus fundamentos.
- Representación: La representación debe dar cuenta no sólo de la descripción de los resultados de la toma de decisiones (Estados financieros), sino de los procesos implicados, mostrando las interrelaciones entre los fenómenos no solo de tipo económico, sino de tipo social a través de procesos contamétricos: "La complejidad de la realidad objeto de la ciencia contable imposibilita o dificulta el conocimiento directo de sus diferentes estados, y por tanto, el análisis prospectivo y retrospectivo de los mismos. Ante tales circunstancias, la Contabilidad se ve obligada a acudir a la utilización de entes representativos con la única finalidad de transmitir su imagen con la fidelidad necesaria" (Gómez, 2009, 16).

- Coordinación: "El método de coordinación llamado de "partida doble -fundamentado en la dicotomía lógica aristotélica - más conocido hoy en día, puede ser aplicado en forma general, es decir, que no se limita a su consideración causal, sino que es posible extenderlo a cualquier doble clasificación resultante del producto cartesiano de dos conjuntos de cuentas o elementos conceptuales y mediante las cuentas de control y su aplicación puede extenderse a la Lógica Deóntica y a los ultraproductos de la moderna teoría de modelos" (Calfell, en su prólogo a la obra "La homogenización de magnitudes en la ciencia de la contabilidad" de Requena, 1977).

- Agregación: "Realizadas las funciones de captación, medición, valoración y representación, es necesario un proceso mediante el cual, y a partir de diversas agregaciones o sumas, se obtengan unos estados sintéticos, que en la literatura contable recibe la denominación de proceso de agregación contable, en aras de la consecución de una visión más sintética y ordenada de la realidad, que posibilite extraer ciertas conclusiones... siendo así como creemos debe interpretarse esta importante función contable; es decir, como aquella, que a través de todo el proceso contable, nos lleva, desde la más simple expresión de la realidad dispersa, a la síntesis representativa de una situación conjunta de la misma" (Gómez, 2009, 19). 
- Análisis e interpretación: Aquí es donde comienza la función de análisis, comprensión y explicación de los fenómenos de la dinámica de las masas patrimoniales: "Conocer las relaciones de causa a efecto que han motivado la situación presente, distinguir aquellos aspectos que han sido positivos, y que conviene reforzar, de aquellos otros que tienen significación negativa, que conviene controlar, anular o cambiar. Corresponde, por tanto, establecer un tratamiento que nos permita dar un pronóstico de curación o mejoramiento de la salud empresarial" (Rocafort, 1983).

- La Contabilidad debe apoyarse en la lógica y la hermenéutica para comprender el verdadero sentido de los hechos expresados tanto en cifras como en expresiones verbales, que son verdaderas comunicaciones sobre la verdad, las que a su vez generan interacciones económicas y sociales, que deben ser evaluadas contextualmente en los momentos del tiempo apropiadas lo que le concede un carácter de ciencia histórica.

\subsection{Evolución hacia una teoría general contable}

Una vez establecidas las premisas básicas, la siguiente tarea en la estructuración de la teoría general contable, consiste en establecer un cuerpo de explicaciones integradas que den cuenta del comportamiento de la riqueza o el patrimonio en su concepción más amplia lo que implica desarrollar el conjunto de teorías interrelacionadas que expliquen las dinámicas patrimoniales. Según Bunge (1989, 413):

"Es una peculiaridad de la ciencia contemporánea el que la actividad científica más importante- la más profunda y la más fecunda- se centre en torno a TEORIAS, y no en torno a la recolección de datos, la clasificación de los mismos o hipótesis sueltas".

Para la ciencia contable es importante avanzar hacia el desarrollo de esas explicaciones sobre las dinámicas patrimoniales, lo que implica para la teoría general lograr integrar esas diversas explicaciones en un tronco común, lógico y coherente, que atienda los diferentes niveles de la realidad estudiada, y de esa manera se extienda en ramificaciones explicativas de la realidad patrimonial. Se exige de esta manera que la ciencia contable avance en la construcción de un conjunto de teorías explicativas como las que se relacionan más adelante y que deben convertirse en el objetivo de la estrategia de desarrollo científico de la Contabilidad, pues mientras no se aboque esta tarea, difícilmente se alcanzará el verdadero estatus científico.

A partir de esos fundamentos explicativos de las dinámicas patrimoniales se deben diseñar las reglas de construcción de los sistemas de representación concretos que respondan a objetivos específicos, lo que origina los diversos sistemas contables que deben ser producto de la operacionalización y aplicación de las teorías que son las verdaderas explicaciones de los fenómenos. Sin embargo este paso fundamental del desarrollo de las teorías explicativas se ha obviado por lo que ya señalábamos sobre el desinterés de quienes detentan del poder disciplinal, dando por sentado que el modelo de generación y distribución de la riqueza es único y universal y que por lo tanto los objetivos de la información deben estar orientado exclusivamente a los dueños del capital. Desafortunadamente se ha caído en una confusión al identificar las reglas de construcción de los sistemas contables con las explicaciones de los sistemas de información, quedándose en la formalización de una tecnología, que solamente tienen el carácter de técnicas para los manejos de información financiera, dejándose de lado la verdadera explicación de los fenómenos que representan esos sistemas de información:

"Existen unos objetivos específicos o necesidades de información dadas, las cuales deben ser cubiertas por un concreto sistema contable. La elección de reglas contables (hipótesis específicas) depende del propósito o necesidad señalados" (García-Casella, 2008).

Entre esas teorías se pueden mencionar algunas que ya han logrado un desarrollo y otras que están por desarrollar:

- La Teoría de los Informes Contables Financieros habla de: a) Teoría del propietario, b) Teoría de la entidad c) Teoría de los fondos (García-Casella, 2008). 
- La teoría de la valoración: Aquí es necesario hacer una integración entre las teorías económicas y contables-financieras para generar nuevos enfoques valorativos en un enfoque interdisciplinar y transdisciplinar : teorías de valor-precio, teorías del comportamiento humano bajo un enfoque valorativo y sus representaciones, Modelos Alternativos de Valuación de Activos y Determinación de Resultados y alternativas de representación contable, teoría del valor económico agregado y sus representaciones, etc.

- La teoría de la circulación y distribución de la riqueza y sus representaciones: Los intercambios entre la empresa y el medio ambiente social y los impactos que deberían incluirse en los Informes Financieros y también en los Informes Sociales o los informes Medioambientales, Estados de la distribución de la riqueza en las unidades sociales empresariales, representaciones del equilibrio social en las entidades patrimoniales privadas y públicas, informes sobre el valor social agregado, equilibrios sociedad-empresainversionistas del mercado de capitales, etc.

- Teoría de la representación, valoración y contabilización del conocimiento como máxima expresión de la riqueza en la sociedad del conocimiento y sus problemas de distribución, acumulación y consumo de los activos intangibles.

- Teoría de la Regulación Internacional de los Estados Contables Financieros como parte de la Teoría de la Contabilidad Financiera que quedaría incluida en la Teoría General de la Contabilidad (García-Casella, 2008).

Esta es solo una muestra de posibilidades teóricas que debe abordar una teoría general contable y desde luego es de aclarar que queda una tarea pendiente, para un programa de investigación orientado al desarrollo de esta teoría general contable y es la de diseñar una estructura jerárquica que parta de leyes generales referentes a la esencia del fenómeno de las dinámicas patrimoniales, hasta llegar a leyes particulares que expliquen los diferentes niveles de la realidad que afronta el problema de la vida desde la perspectiva patrimonial o de la riqueza y finalmente definir el conjunto de reglas de construcción de los sistemas contables, que debe ser el eslabón final de la cadena teórica de generación de conocimientos contables.

\subsection{Alternativas de desarrollo de la teoría gene- ral contable}

Una vez se han logrado estructurar en un cuerpo unificado, el conjunto de teorías que apunten a la comprensión y explicación de los movimientos de la riqueza en su expresión patrimonial en su acepción más amplia y se haya logrado estructurar el entretejido sistémico entre ellas (partiendo de la premisa establecida: La Ciencia contable debe describir y determinar los diferentes niveles de la vida en su expresión patrimonial en el sentido amplio, cada uno de los cuales deben ser entendidos, interpretados y explicados no solo al interior de cada nivel, sino en su proceso de emergencia, transformación y mutuas interacciones entre esos niveles), la alternativa que se abre es el modelamiento contable como expresión de la contametría (reunión de instrumentos matemáticos, estadísticos, económicos, contables, de simulación de los fenómenos patrimoniales) que permitan estudiar, comprender, explicar y simular decisiones en el entramado del movimiento patrimonial de las unidades sociales empresariales y sus relaciones con el entorno social y sus impactos en la distribución y consumo de la riqueza:

"en materia de modelización tenemos que tener en cuenta: a) No existe un único modelo científico contable capaz de explicar la compleja realidad de las organizaciones de la sociedad. b) Para construir los modelos contables se necesita: I. Abstracción II. Generalidad" (García-Casella, 2008).

Para que estos desarrollos evolucionen, es de prever la generación de una crisis y una revolución paradigmática, lo que necesariamente implica la confrontación de paradigmas, teorías y modelos contables entre grupos diversos que luchan por dominar, lo cual socialmente se expresa en una politización del proceso de regulación contable, significando ello que es necesario estudiar los posibles desarrollos del campo contable, entendido éste como la integración 
de intereses profesionales y disciplinales, lo cual de por sí es un campo de estudio que debe hacer parte de una teorización general de la contabilidad.

\section{Conclusiones}

El camino por recorrer en el proceso de estructuración de una teoría general contable es amplio y apasionante, pero exige un esfuerzo mancomunado de los profesionales e investigadores de la Contaduría en asocio con las demás profesiones que hemos denominado concomitantes.

Los esfuerzos de formalización liderados por Mattessich y Lopes de Sá, han contribuido a desarrollar un modelo de sistematización y matematización de la teoría general contable, pero se desconoce por la mayoría de los profesionales e incluso de investigadores por lo menos de nuestro país, lo que impide que se aproveche para extender su cobertura desde lo patrimonial económico hacia lo patrimonial humano-cultural, territorial y social; y sobre todo que se incorporen diferentes teorías explicativas de los diversos componentes de la dinámica patrimonial ampliada.

Para el progreso de la formalización de la teoría general contable es necesario realizar un amplio inventario de los diferentes aportes de las diferentes corrientes del pensamiento a dicha estructura, lo que implica estudiar a profundidad el estado del arte del esfuerzo disciplinal orientado en ese sentido, lo cual exige que nuestros profesionales se formen en los conceptos de la epistemología científica aplicados a la ciencia contable.

Se debe dar un salto paradigmático para pasar de los esfuerzos dedicados a la estructuración de las reglas de construcción de los sistemas de información contable de lo patrimonial económico a lo patrimonial humano-cultural, territorial y social, retomando la función científica de explicar, comprender e interpretar los fenómenos de las dinámicas patrimoniales económicas, humano-cultural, territorial y social, que le den sustento a los diferentes modelos de representación expresados en sistemas contables correspondientes a diversos niveles de la realidad de la vida.
El enfoque de la complejidad es un gran respaldo epistemológico para la construcción de la teoría general contable, pues amplía el marco de comprensión de los fenómenos patrimoniales de las células sociales, recurriendo a principios como la recursividad, la emergencia, la dualidad de lo objetivo y lo subjetivo, las interrelaciones y la influencia mutua en ciclos en espiral de causas a efectos, la auto-organización, entre otros.

\section{Referencias}

Araujo, J. (2007). Los recursos: objeto de estudio de la Contabilidad. En: Contaduría Universidad de Antioquia, 50: 177-186

Avellaneda, C. (2009). "El patrimonio y los ciclos de operaciones financieras". En: Revista Criterio Libre de la Facultad de Ciencias Económicas, Administrativas y Contables de la Universidad Libre, 7(11).

Avellaneda, C. \& Ortiz, J. (2012). "Explicación contamétrica de las dinámicas patrimoniales desde una concepción social". En: Revista Criterio Libre de la Facultad de Ciencias Económicas, Administrativas y Contables de la Universidad Libre, 10 (17).

Bachelard, G. (1987). "La formación del espíritu científico". Editorial Siglo XXI. México.

Bertalanffy, Ludwig Von (2006). "Teoría General de Sistemas". Fondo de Cultura Económica. México.

Bourdieu, P. (1999). Intelectuales, política y poder. Editorial Universitaria: Buenos Aires.

Bourdieu, P. (2003). El oficio de científico: ciencia de la ciencia y reflexividad. Editorial Anagrama. Barcelona, España.

Bunge, M. (1996). La Ciencia, su método y su filosofía. Panamericana Editorial. Bogotá.

Bunge, M. (1989). La investigación científica: su estrategia y su filosofía. Traducción de Manuel Sacristán - $2^{\mathrm{a}}$ edición corregida - Barcelona. Editorial Ariel S.A.

Cañibano, L. (1979). "Teoría actual de la Contabilidad". Ediciones ICE, Madrid España.

Capra, F. (2003). "Las conexiones ocultas". Implicaciones sociales, medioambientales y biológicas de una nueva visión del mundo. Editorial Anagrama. Barcelona.

Capra, F. (2004). "La trama de la vida". Editorial Anagrama. Barcelona.

Chatfield, M. (1979). "Estudios contemporáneos sobre la evolución del pensamiento contable". Ed. Dickenson. México.

Chua, W. F. (1986). "Desarrollos radicales en el pensamiento contable". En: Gómez, M. \& Ospina, C. (2009). "Avances interdisciplinarios para una comprensión crítica de la Contabilidad, textos paradigmáticos de las corrientes heterodoxas", U. de Antioquia - U. Nacional de Colombia.

Coelho, L. (2004). "Aportes sobre la doctrina científica del Neopatrimonialismo". En: Revista Internacional Legis de Contabilidad \& Auditoría, Octubre - Diciembre de 2004.

Fernández, L. (2003) "Teoría general y metodología contable". Facultad de Ciencias Económicas - Universidad Nacional de La Plata. Consultado en www.econ.uba.ar/

Franco, R. (2011). "Reflexiones contables". Editado por Universidad Libre. Bogotá, Colombia. 
García-Casella, C. (2001) Elementos para una Teoría General de la Contabilidad. Buenos Aires. Editorial La Ley S.A.

García-Casella, C. (2008) "Necesidad de reconstruir la teoría de la contabilidad financiera". En: Contabilidad y Auditoría, 27, año 14, junio 2008. Consultado en: http://www.econ.uba.ar/www/ servicios/Biblioteca/revista_cya/27/garciacasella.pdf

Gómez, R. (2009) La ciencia contable: fundamentos científicos y metodológicos. Consultado en: cyta.com.ar/biblioteca/bddoc/ bdlibros/ciencia contable/

Gómez, M. (2012). Comentarios sobre el aprendizaje-construcción de la teoría contable. Consultado en: http://www.docentes.unal. edu.co/mgomezv/docs/Comentarios

Guerrero, G. (2003) "Enfoque semántico de las teorías. Estructuralismo y espacio de estados: coincidencias y divergencias". En: Revista praxis filosófica. Consultado en: http:// praxis.univalle. edu.co/números/n16. Número 16 Enero-Junio de 2003.

Horkheimer, M. (2000). "Teoría tradicional y teoría crítica". Editorial Paidós. Barcelona.

Ibáñez, E. (2010). "El estatus epistemológico de la contabilidad", en revista contabilidad y decisiones. Instituto de Contabilidad, dependiente de la Facultad de Ciencias Económicas y de Administración, de la Universidad Católica de Córdoba. Número 2, Año 2 - 2010. Consultado en http://www.ucc.edu. ar/portalucc/archivos/File/FACEA/Instituto_de_Contabilidad/ revista-n2-inst-contabilidad.pdf.

Ijiri, Y. (1975). Theory of accounting measurement. Sarasota: American Accounting Association.

Kant, I. (1984). "Crítica de la Razón Pura". Ediciones Alfaguara. Madrid. Traducción de Pedro Ribas.

Lopes de Sá, A. (1992). "Fundamentos lógicos de la teoría de las funciones sistemáticas del patrimonio hacendal". En: Revista Cuadernos, 23: 13-45. Consultado en: http://externos.uma.es/ cuadernos/pdfs/pdf492.pdf.

Lopes de Sá, A. (2007). Doctrinas, escuelas y nuevas razones de entendimiento para la ciencia contable. En: Revista Contabilidad \& Auditoría de Legis, No 30, abril-junio de 2008.

Luhmann, N. (1990). "Sociedad y sistema: La ambición de la teoría”. Editorial Paidós. Barcelona.

Mardones, J. (1994). Filosofía de las ciencias humanas y sociales. Editorial Anthropos. Barcelona.

Mattessich, R. (1995). Critique accounting. Examination of the foundations and normative structure of an applied discipline. Westport, Connecticut: Quorum Books, Greenwood Publishing Group.

Mattessich, R. (2002) Contabilidad y Métodos Analíticos: Medición y proyección del Ingreso y la Riqueza en la Microeconomía y Macroeconomía. Buenos Aires. Editorial La Ley. Traducción de García Casella, C. L. \& Rodríguez de Ramírez M.C. del original en inglés editado en 1964 por Richard D. Irwin Inc. Homeword Illinois. USA.

Maturana, H. (1990). "El árbol del conocimiento: las bases bilógicas del conocimiento humano". Editorial Debate. Madrid.
Mejía et al. (2005). "Contabilidad y racionalismo crítico". Universidad Libre

Mejía, E. (2004). Evolución del pensamiento contable de Richard Mattessich.

Montilla, O. de J., Montes, C. \& Mejía, E. (2005). Armonización o estandarización contable internacional. Cali, Colombia: Universidad de Libre.

Morín, E. (1985). El Método. Editorial Cátedra. Madrid.

Morín, E. (2000). Introducción al pensamiento complejo. Editorial Gedisa. Barcelona

Nagel, E. (1968). La estructura de la ciencia: problemas de la lógica de la investigación científica. Editorial Paidós. Buenos Aires.

Nepomuceno, V. (2008). Teoría da Contabilidades. Curitiba: Juruá

Ordóñez, S. (2007) ¿Contribución de la investigación contable a la formación del contador público en Colombia? Consultado en: http://administracion.univalle.edu.co/ Colombia.pdf:

Ortiz, J. (2009). "Fronteras de la investigación contablefinancieraeconómica: autonomía e interdisciplinariedad". En: Revista Facultad de Ciencias Económicas, Universidad Militar Nueva Granada, XVII (1).

Ortiz, J. (2010). "La complejidad y la teoría contable". En: Revista Criterio Libre, 8 (13): 231-250.

Ortiz, J. (2012). "La medición contable bajo un enfoque interdisciplinar y sistémico". Ponencia presentada en el Primer Simposio Internacional de Contametría, U Libre, Bogotá, Abril 2012.

Pinilla Monclus, J. (1976). Una nueva fundamentación axiomática de la contabilidad. En: Revista española de financiación y contabilidad, V (15): enero-marzo 1976.

Popper, K. (1962). La lógica de la investigación científica. Madrid: Editorial Tecnos.

Requena, J. (1977). "La homogenización de magnitudes en la ciencia de la Contabilidad". Madrid: Ediciones Ice.

Rocafort, N. (1983). Análisis e interpretación de balances. Ed. Hispano Europea, Barcelona.

Rodríguez, D. (2011). "Formulación de una estructura teórica para la contabilidad ambiental". En: Libre empresa, Universidad Libre (Cali, Colombia), 16: 101-120.

Romero, H. (2001). Teorías científicas y teoría contable. En: Revista Legis del Contador, No 8.

Ryan, B., Scapens, R. \& Theobald, M. (2004). Metodología de la investigación en Finanzas y Contabilidad. Ediciones Deusto. Barcelona.

Túa Pereda, J. (1984). "Principios y normas de contabilidad", Instituto de Planificación contable, Ministerio de Economía y Hacienda de España.

Túa Pereda, J. (1995). Lecturas de Teoría e Investigación Contable. Centro Interamericano Jurídico Financiero. Medellín. Colombia.

Vásquez, P. \& Bongianino, C. (2008), Principios de teoría Contabilidad. Editado por Aplicación Tributaria S.A. Buenos Aires, Argentina.

Villarreal, J. (2009). "Bases conceptuales para la construcción de teoría contable". En: Criterio Libre, 7 (11): 167-190. 